\title{
Can COVID-19 and environmental research in developing countries support these countries to meet the environmental challenges induced by the pandemic?
}

\author{
Qiang Wang ${ }^{1,2} \cdot$ Chen Zhang ${ }^{1,2}$ \\ Received: 14 January 2021 / Accepted: 17 March 2021 / Published online: 29 March 2021 \\ (C) The Author(s), under exclusive licence to Springer-Verlag GmbH Germany, part of Springer Nature 2021
}

\begin{abstract}
Meeting the huge impact of COVID-19 on the environment requires better research on pandemic and pollution. What is the research capacity of the COVID-19 and environment in developing countries? Can this research capacity support developing countries to deal with the environmental challenges induced by the pandemic? This work is addressed to comprehensively assess the research capacity of the COVID-19 and environment in developing countries using bibliometric analysis techniques and content analysis approach to mining the Web of Science database. The results of data mining were unexpected: the global leader of the COVID-19 and environmental research was not these developed countries, but these developing countries so far, the end of 2020. Developing countries have published more papers on the pandemic and environment than developed countries, and developing countries also dominate pandemic and environmental research in terms of research institutions and authors. The results showed that (i) the impact of COVID-19 and the environment was bidirectional; (ii) energy consumption has posed great impact on environment; (iii) application of big data and artificial intelligence played an important role in improving environmental quality during the COVID-19 pandemic. Finally, policy recommendations such as formulating relevant policies and environmental standards, strengthening international exchanges and cooperation, and adjusting and improving energy consumption structure that were put forward for developing countries to meet the environmental challenges induced by the pandemic were offered.
\end{abstract}

Keywords COVID-19 $\cdot$ Environment $\cdot$ Bibliometric analysis $\cdot$ Content analysis $\cdot$ Developing countries

Responsible Editor: Philippe Garrigues

\section{Highlights}

-Assessing research capacity of the pandemic and pollution in developing countries.

-Bibliometric analysis techniques and content analysis approach were used to mining data.

- The global leader of the COVID-19 and environmental research was the developing countries.

-Impact of COVID-19 and the environment was bidirectional.

-The application of big data and artificial intelligence played an important role in improving environment.

Qiang Wang

wangqiang7@upc.edu.cn

1 School of Economics and Management, China University of Petroleum (East China), Qingdao, Shandong 266580, People's Republic of China

2 Institute for Energy Economics and Policy, China University of Petroleum (East China), Qingdao, Shandong 266580, People's Republic of China

\section{Introduction}

Coronavirus disease 2019 (COVID-19) is a major public health event. COVID-19 broke out in multiple locations around the world and spread rapidly. It has the characteristics of wide range of infection, rapid spread, and difficulty in prevention and control. It has seriously threatened the survival of human beings. According to the latest data from the World Health Organization (WHO), there are more than 37 million confirmed cases of the novel coronavirus worldwide and more than 1.07 million deaths from the novel coronavirus worldwide. More than 200 countries and regions have been affected by the epidemic. The COVID-19 outbreak has not only significantly affected the supply chains of manufacturers and retailers around the world, the development of the tourism industry has been restricted, education methods have begun to shift to online distance learning, and business organizations are paying more and more attention to the application of 
digitization and artificial intelligence, which has caused a great impact on global environmental conditions and supervision(Krishnamurthy 2020; Lee and Trimi 2021; Sharma et al. 2020; Sigala 2020; Verma and Gustafsson 2020). In response to this major public health incident, various countries and regions have implemented a series of control measures and adopted a closed management model to reduce contact between people. Lockdown measures have greatly reduced social, economic, industrial, and social activities, and therefore reduced various types of pollution emissions, and improved the global environment (Arora et al. 2020). Governments in countries and regions around the world have taken mandatory precautions by using alcohol disinfectant, hand sanitizer, gloves, and masks to avoid the harm caused by COVID-19, especially vulnerable groups such as middleaged and elderly people, children, and the infirm, which produces a large amount of medical waste and domestic garbage. If medical waste and domestic garbage are not handled properly, it will pollute the atmosphere, groundwater, surface water, and soil, which is not conducive to environmental supervision and sustainable development (Bashir et al. 2020). In addition, the emergency purchase of disposable products has increased production and consumption, thus hindering global efforts to reduce plastic pollution (Sarkodie and Owusu 2020). The occurrence and spread of COVID-19 are closely related to environmental issues such as air pollution and water pollution. A survey of global environmental conditions found that environmental conditions with suitable temperature, high air humidity and rainfall, and high air pollution are more conducive to the spread of COVID-19 (Ahmed and Ghanem 2020). And the COVID-19 virus can survive for many days in untreated sewage. Some countries and regions with large populations but low sewage treatment facilities have a very high probability of being infected by the COVID-19 virus (Bhowmick et al. 2020; Carducci et al. 2020). A low-temperature environment can prolong the activity of the COVID-19 virus. An investigation showed that the COVID-19 virus was detected in frozen and refrigerated food (including its packaging materials), and there were two repeated outbreaks of the epidemic related to contaminated food. This proves that COVID-19 can be spread through the contaminated food cold chain (Han et al. 2020).

Therefore, the environmental sustainability in the context of the pandemic has aroused widespread concern in the international community. The COVID-19 epidemic was first discovered in Wuhan, China, in December 2019. The countries that reported COVID-19 cases first after the outbreak in China were Thailand, Japan, South Korea, Taiwan, and Vietnam, then spread to most countries and regions around the world. Since the outbreak of COVID-19, it has rapidly spread to most developing countries around the world, and the number of deaths from COVID-19 has gradually increased in developing countries such as India and Iran. Developing countries have resisted greater pressures on safety, health, and environmental protection, and have an urgent need to deal with this sudden challenge. In order to better respond to COVID-19, most research institutions and scholars in developing countries have taken the lead in researching the impact of the COVID-19 epidemic and its driving factors, and found that there is a close relationship between the environment and the COVID-19 epidemic. Most developing country governments and academics have learned lessons from this epidemic and plan for a transformation to create a greener and more resilient environment. The core of these transformations is to obtain timely highquality, classified data analysis and statistics, which will help the government to formulate effective and fair measures and policies (Editorial 2020).

In this context, the systematic analysis of COVID-19 and the environment is particularly important. To solve the root cause of COVID-19 is that we need to clarify the complexity between the environment and the epidemic. Only by revealing their interaction can we better prevent and control new infectious diseases (Chin et al. 2020). China and other developing countries were the first to be pressured by the safety, health, and environment under the influence of the COVID-19 epidemic, and their research institutions and scholars took the lead in conducting related research. The research on COVID-19 and the environment in developing countries has certain representative significance. Therefore, we should examine the current status of research in developing countries, which is of great significance for strengthening the research on COVID-19 and the environment, restraining the further spread of the COVID-19 epidemic, and building a greener and more environmentally resilient world. The author systematically analyzed and summarized the relationship between COVID-19 and the environment, and came up with comprehensive strategies to prevent epidemics similar to COVID-19 (Coccia 2020). However, due to the suddenness, infectiousness, and spread of the epidemic, current research has not yet formed a systematic consensus on this. Therefore, this article uses content analysis and bibliometric analysis to systematically review and analyze the literature on COVID-19 and the environment in the core database of the scientific network.

This article aims to analyze the global overview of COVID-19 and environmental research, predict the development direction of the environment after the epidemic, assess the environmental challenges that developing countries face while actively responding to the COVID-19 epidemic, and propose reasonable policy recommendations. Scientific research input and output mainly include researchers engaged in the research field, research institutions, and the number of published papers, which are important indicators to measure the development level of a research field ( $\mathrm{Xu}$ et al. 2019). Therefore, this article uses bibliometric analysis, visual analysis, and content analysis methods to analyze the COVID-19 and environmental research literature included in the Web of 
Science (WOS) database from the four perspectives of total literature, research institutions, publication journals, highyield authors, and draw social network icons (Kim and Hastak 2018). Specifically, this article discusses the following three aspects: (1) analyze the global profile of the COVID-19 pandemic and environmental research; (2) what role does the research on COVID-19 and the environment in developing countries play in the world on the basis of the current status of global COVID-19 pandemic and environmental research?; (3) discussing environmental challenges faced by developing countries and its future development prospects.

The main content of this article includes five chapters. "Methods and data sources" describes the methodological framework and data sources of this research; "The role of developing countries in COVID-19-environmental research" discusses the global overview of COVID-19 and environmental research from the perspective of total literature, research institutions, and high-yield authors, and reveals the role of developing countries in global COVID-19 and environmental research; "Challenges and solutions" uses bibliometric analysis methods to point out the challenges faced by developing countries and put forward reasonable policy recommendations; "Conclusions" summarizes the full text.

\section{Methods and data sources}

\section{Research design}

Scientific literature can not only reflect the level of development and the direction of research in a certain subject area, but also reflect the soft power of a country or region (Albort-Morant and Ribeiro-Soriano 2016; Zhang et al. 2015). Scholars are committed to using different literature review methods to understand and organize early research. Bibliometrics is a kind of information analysis method widely used in academic circles. It can make full use of the existing knowledge base to comprehensively analyze the previous research results and provide more objective and reliable analysis (Wang and Li 2017). Bibliometrics is an advanced technology for summarizing, analyzing, and visualizing various disciplines (Liao et al. 2018). Bibliometric analysis, which integrates mathematics, statistics, and philology, is a quantifiable comprehensive knowledge evaluation system. Moreover, bibliometric analysis organically combines qualitative analysis with quantitative analysis, breaking the limitations of traditional information analysis methods that cannot be quantified and repeatable. At present, most scholars use bibliometric methods to evaluate and analyze research results in this field. For example, visual analysis is used to explore the current situation of informatization (Liao et al. 2018; Tran et al. 2019), systematically visualize the future development trends of green building field (Liu et al. 2020), operational research and management science development trends in recent decades (Merigo and Yang 2017), and the development prospects of emerging technologies and renewable energy, which provide a strong theoretical proof for environmental policy making (Hache and Palle 2019; Sarkodie and Strezov 2019). Bibliometric analysis is considered as a systematic analysis technique in literature research and literature analysis, which is often used to retrieve and analyze literature in order to obtain useful information. In academia, bibliometrics is a classic approach of information analysis. However, most bibliometric studies have their own limitations, such as narrow range of data selection, incomplete perspective of the research field, and limitations of descriptive analysis. In order to avoid the above problems, this article will use bibliometric analysis, visual analysis, and content analysis. Visual analysis is mainly applied to massive data association analysis, and it is also a widely used information analysis technique. In this paper, the visualization analysis visualizes the analysis results by drawing mapping knowledge domains; content analysis can achieve a deeper, more accurate and comprehensive understanding of the content of the literature, draw scientific and complete conclusions, and obtain connections that are difficult to find from qualitative analysis. This article uses bibliometric data to show the evolution of hot topics, identify the impact of milestone studies, analyze the relationship between articles and references, and use semi-automatic methods to further analyze the content of highly cited articles in co-citation analysis. We used content analysis and visual analysis methods to more accurately capture the content of the relationship between COVID-19 and environmental pollution, systematically expand scientific mapping methods, and provide future development paths for the research field of viral infectious diseases and environmental pollution. Bibliometric analysis, visual analysis, and content analysis are the mainstream methods used in literature review (Lopes and de Carvalho 2018). This paper will follow the standard scientific mapping workflow, divided into four stages for analysis: (1) design of research questions; (2) determination of database, keywords, time range, and other factors; (3) data collection; (4) bibliometric analysis, visual analysis, and content analysis (Aria and Cuccurullo 2017), as shown in Fig. 1.

\section{Data collection}

In order to solve the research problems of this paper, the research content will be carried out around the following three aspects: (1) analyze the global profile of the COVID-19 pandemic and environmental research; (2) what role does the research on COVID-19 and the environment in developing countries play in the world on the basis of the current status of global COVID-19 pandemic and environmental research?; (3) discussing environmental challenges faced by developing countries and its future development prospects. In response to the research question, this article collects relevant data. In bibliometric analysis, it is very important to obtain reliable 


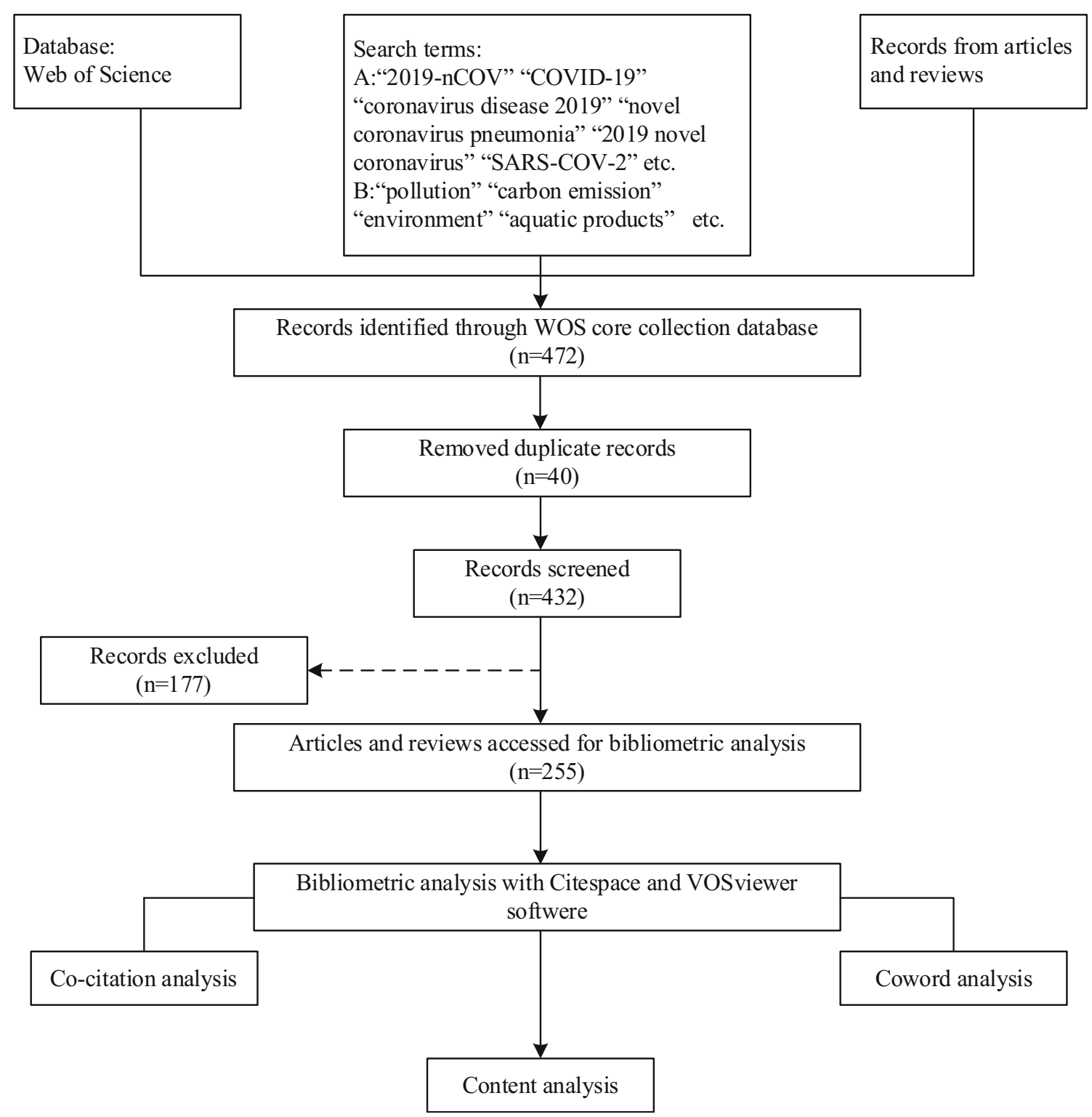

Fig. 1 Workflow of the system analysis

data from scientific literature. In order to enhance the authenticity, validity, and reliability of the data, this article will follow the standard to collect the initial sample. Many studies have compared mainstream databases such as Web of Science (WOS), Scopus, and PubMed, and found that WOS can produce similar results in bibliometric analysis. WOS Core Collection has a high proportion of exclusive journals in social sciences and humanities, and WOS Core Collection can provide higher standards of literature data to improve data processing efficiency (Martín-Martín et al. 2018; Mongeon and Paul-Hus 2016). In this study, keywords related to COVID-19 and environmental pollution were selected from the WOS database to search for relevant documents in order to retrieve all relevant publications. We browsed through a large number of literature case libraries, news materials, and other channels for keyword screening and obtained a more comprehensive expression of the "COVID-19 epidemic" and the environment. Keywords related to COVID-19 are "2019-nCOV," "coronavirus disease 2019," "novel coronavirus pneumonia," "2019 novel coronavirus," "SARS-COV-2," "2019 novel coronavirus diseases," "novel coronavirus," and so on. Keywords related to environmental pollution include "carbon emission," "environment," "pollution," "air pollution," "waste," "garbage," and "aquatic products," and so on. On this basis, we use the "AND," "OR," "NOT," "*," and other operators in the WOS database to match the selected keywords to avoid subjective keyword selection, and ensure the objectivity and comprehensiveness of the literature search results. Because the COVID-19 outbreak occurred in December 2019, we limited the time range from December 2019 to October 2020 to ensure the timeliness and pertinence of the article. According to the search criteria, 472 articles were 
obtained. Subsequently, this research manually deleted 40 repetitive articles by integrating different types of topics and institutions, retained 432 articles. In the next screening stage, this study selects documents based on the following criteria: (1) delete non-English articles and only use English articles; (2) select articles with document types as "Article" and "Review"; (3) delete articles not related to COVID-19 and environmental pollution, and select articles that are closely related to the scope of this article. Therefore, 255 articles published on the WOS database were exported for bibliometric analysis, visual analysis, and content analysis. From December 2019 to October 2020, a total of more than 200 scholars conducted research on COVID-19 and environmental pollution, and 42 countries and 187 institutions published articles. Obviously, various countries and regions are paying more and more attention to the relationship between COVID-19 and environmental pollution, this research field is still in the development stage, and different scholars from different countries have made contributions to this research field (Verma and Gustafsson 2020). Therefore, it is very important to process the data included in the bibliometric analysis, visual analysis, and content analysis. This article will process the data information according to the following principles: (1) process the same author with different author names and different authors with the same author name; (2) when the authors of the article are from different countries and institutions, the country and institution of the article are determined by the first author and the complete address of the institution; (3) in the keyword analysis, the keywords with the same meaning are standardized as a single keyword (Goh and See 2020).

\section{Data analysis}

This article first analyzes 255 documents through the bibliometric method. Software tools such as CiteSpace, VOSviewer, R, CitNetExplorer, and Vantage can perform bibliometric analysis and greatly improve work efficiency. CiteSpace and VOSviewer are Java applications that can be used to visually analyze research trends and patterns in scientific literature. They are powerful visual data analysis platforms that can assist manual operations to analyze the data and make a complete analysis chart. Visualizing the research results can reduce or avoid errors caused by manual analysis, thereby improving the accuracy and reliability of the results. Additionally, visualization software greatly improves work efficiency. In recent years, they have been widely used in many fields for bibliometric analysis (Hu et al. 2019). Therefore, this article will use the knowledge graph software CiteSpace and cooperate with the VOSviewer software to perform visual analysis; the visualization process mainly includes three main steps: similarity standardization processing, clustering, and visualization methods.

\section{(1) Similarity standardization processing}

Data preprocessing is the first step of visual analysis and the basis of data visual analysis. In order to obtain ideal results and better display the relationship between the data, it is necessary to ensure the quality of the preprocessed data. Dice is one of CiteSpace's standardized algorithms. The Dice similarity coefficient can calculate the similarity of two strings:

Dice $=\frac{2 * \operatorname{comm}\left(S_{1}, S_{2}\right)}{\operatorname{leng}\left(S_{1}\right)+\operatorname{leng}\left(S_{2}\right)}$

In formula (1), $\operatorname{comm}\left(S_{1}, S_{2}\right)$ is the number of the same characters in $S_{1}$ and $S_{2}$, and leng $\left(S_{1}\right)$ and leng $\left(S_{2}\right)$ are the lengths of the strings $S_{1}$ and $S_{2}$.

\section{(2) Clustering}

Clustering is to group data objects into multiple classes or clusters. The principle of division is that the objects in the same cluster have good similarity, but the objects between different clusters are quite different. In the function menu of CiteSpace software, the cluster menu contains algorithms that can be selected during the clustering process, including clustering algorithms, likelihood ratio (LLR) algorithms, and mutual information (MI) algorithms.

The clustering algorithm belongs to the interclass distance algorithm in the hierarchical clustering algorithm.

$D_{p q}^{2}=\frac{1}{n_{p} n_{q}} \rightarrow_{x_{j}} \in \omega_{q} \sum_{x_{i} \in \omega_{p},} d_{i j}^{2}$

In formula (2), $p$ and $q$ are two clusters. The distance between them is determined by the average distance between the units $i$ and $j$.

LLR clustering algorithm is as follows:

$\mathrm{LRR}=\log \frac{p\left(C_{j} \mid V_{i j}\right)}{p\left(\bar{C}_{j} \mid V_{i j}\right)}$

In formula (3), it is assumed that for the category $C_{j}$, the frequency, concentration, and dispersion of the word $W_{i}$ constitute a vector $V_{i j}$. LLR is the log-likelihood ratio of the word $W_{i}$ to the category $C_{j} . p\left(C_{j} \mid V_{i j}\right)$ and $p\left({ }^{-} C_{j} \mid V_{i j}\right)$ are the density functions of $W_{i}$ in categories $C_{j}$ and ${ }^{-} C_{j}$, respectively.

MI clustering algorithm is as follows:

$\operatorname{MI}(w, c)=\sum_{w, c} p(w, c) \log \frac{p(w, c)}{p(w) p(c)}$

In formula (4), $p(w, c)$ is the co-occurrence probability of $w$ and $c ; p(w)$ and $p(c)$ are the probability of occurrence of $w$ and $c$ respectively. 


\section{(3) Visual analysis}

In order to fully grasp the research hotspots in this field, this article introduces the content of this research field from multiple angles, constructing author cooperation network, national cooperation network, institution cooperation network, and keyword co-occurrence network to comprehensively analyze the research situation of COVID-19 and the environment. The size of the nodes in the generated collaborative network graph represents the number of papers published by authors, institutions, or countries; the annual ring of the node represents the number of papers published in different years; and the connection between the nodes represents the strength of the cooperation relationship between each other. The size of nodes in the network graph indicates the frequency of each keyword, and the connection between nodes indicates the strength of co-occurrence. In addition, "betweenness centrality" will often appear in subsequent analysis. "Betweenness centrality" is an indicator that reflects the importance of node positions in the network diagram. Using a purple circle for this type of literature (or authors, journals, and institutions) to highlight the key points, nodes whose betweenness centrality exceeds 0.1 are called key nodes, which may lead to breakthrough discoveries. Nodes between groups will attract more attention because they are more likely to lead to new trends (Gao et al. 2020).

In the literature obtained by bibliometric analysis, not all citations are equally important, and citations may be irrelevant (Cheng et al. 2018). In order to overcome this shortcoming of bibliometric analysis, this article will conduct content analysis, use content analysis to identify valuable information in text data, describe the characteristics of full-text articles in depth, and form a structured framework to reveal the global overview of COVID19 and environmental research. Therefore, this article uses the methods of bibliometric analysis, visual analysis, and content analysis to systematically review and analyze countries, institutions, and authors and elaborate the global overview of COVID19 and environmental research. Then, this article further evaluates the role of developing countries in COVID-19 epidemic and environmental research, summarizes the environmental challenges and future development prospects faced by developing countries, and proposes corresponding countermeasures.

\section{The role of developing countries in COVID-19-environmental research}

\section{Global research landscape of COVID-19-environment research}

\section{The relativity between COVID-19 and the environment}

This article uses content analysis to identify valuable information in text data, describes the characteristics of the full-text article in depth, and integrates bibliometric analysis to form a structured framework to reveal the relationship between COVID-19 and the environment. This research examines the content of each article of 255 articles, explores the characteristics of each article in detail, and categorizes all articles in accordance with the principles and methods of content analysis. The results found that $14.5 \%$ of the articles (37 articles) used different research methods to compare and evaluate the global air quality before and after the COVID-19 outbreak. $22.7 \%$ of the articles (58 articles) found that since the outbreak of COVID-19, various countries and regions around the world have implemented a series of closed measures. These measures have reduced the movement of people, economic activities, and transportation activities, thereby improving environmental quality conditions. $21.2 \%$ of articles (54 articles) found that countries or regions with severe air pollution would increase the survival rate of the COVID-19 virus and promote the spread of COVID-19. In addition, 5.1\% of the articles (14 articles) found that contaminated water and food cold chains also promote the spread of COVID-19, which is not conducive to the prevention and control of COVID-19.3.5\% of the articles ( 9 articles) found that in this process, the massive reduction in industrial and commercial activities has reduced the global energy demand, and the global demand for renewable and non-renewable energy has declined. $3.1 \%$ of the articles (8 articles) further research found that the decline in energy demand during the COVID-19 epidemic has led to a substantial reduction in global carbon emissions. On the other hand, during the period of COVID-19, the preventive measures of various countries have had a negative impact on the environment to a certain extent. $11.4 \%$ of the articles (29 articles) found that during the epidemic prevention and control period, various countries and regions produced a large amount of medical and health waste, disposable products, and plastic waste. The unreasonable treatment of these sanitary garbage has caused damage to the environment. $9.4 \%$ of the articles (24 articles) realized the important role of big data and artificial intelligence in the prevention and control of the epidemic, and $8.6 \%$ of the articles (22 articles) believed that COVID-19 had changed the way people interact with the environment (Fig. 2h, Table 1).

\section{Bibliographic coupling analysis}

Articles This article conducts a bibliographic coupling analysis on the 255 collected documents to better understand the theoretical basis of these documents. The results show that the most extensive collection of relevant documents contains 104 papers, accounting for $40.7 \%$ of the data set, which indicates that a systematic study on the relationship between COVID19 and the environment has not yet been formed. Figure 3 shows the bibliographic coupling of articles. It can be seen from Fig. 3 that the study with the highest literature coupling 


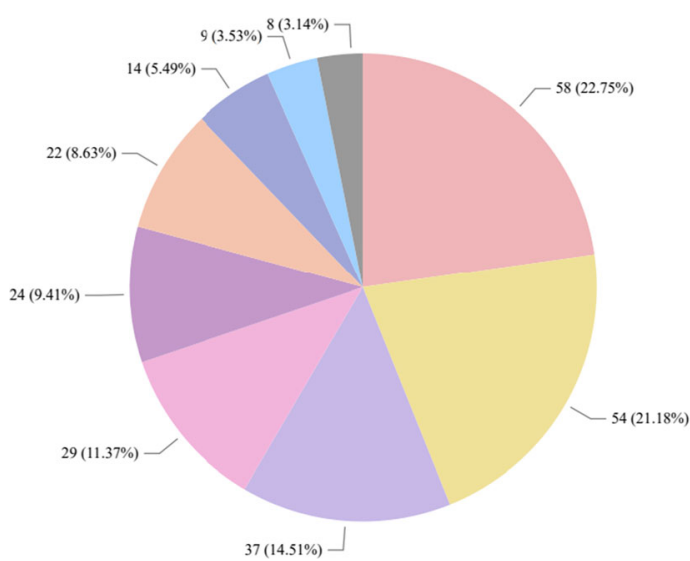

Fig. 2 Frequency of paper by content analysis

index is the articles from Conticini, Ogen, Zambranomonserrate, Coccia, Kondo nakada, and Gautam.. It can be seen from Fig. 3 that Conticini, Ogen, and Zambranomonserrate are widely used in the current research literature on the relationship between COVID-19 and the environment, and formed several clusters.

Journals According to the minimum threshold requirement, Fig. 4 shows some of the 88 journals. Through the bibliographic coupling analysis of journals, we found that Science of The Total Environment, International Journal of Environmental Research and Public Health, Environment, and Development and Sustainability are the three journals with the highest bibliographic coupling index, and these journals have strong persuasive power in the field of environmental research. Many articles in these journals mention the COVID-19 pandemic, indicating that COVID-19 does have an impact on the environment and the research on COVID19 and the environment closely follows the frontiers of academic research. In addition, we also found other types of journals that revealed the multiple impacts of the
COVID-19 pandemic on the environment, as shown in Fig. 4, such as Food and Chemical Toxicology, which shows that COVID-19 is also related to food pollution. Researchers should pay more attention to the diversified impact of COVID-19, strengthen knowledge exchange and cooperation, and deepen the research on the driving factors and impact of COVID-19.

Authors In the data we collected, there are a total of 1197 authors; however, only 97 authors have published at least two articles on the relationship between COVID-19 and the environment. Figure 5 is the density map of the authors' literature coupling analysis. It can be seen that Pal Swades, Benchrif Abdelfettah, and Huang Wei-Syun are the three authors with the highest literature coupling index. The analysis revealed the situation of researchers on the relationship between COVID-19 and the environment. Due to the suddenness of the epidemic, researchers in this field have not formed a relatively stable scientific research cooperation group, which is not conducive to the exchange and sharing of knowledge.

\section{Developing countries' role in global COVID-19- environment paper output}

This article traces the information recorded in the scientific literature and finds that more than forty countries or regions around the world have participated in the investigation and study of the relationship between COVID-19 and environmental pollution and then calculate the total number of publications in these countries. In Fig. 6, this article uses the depth of color to distinguish the country's active participation in epidemic and environmental research. Table 2 lists the total citation frequency and average citation frequency of national publications and ranks them from high to low to get the top ten countries.
Table 1 Frequency of paper by content analysis

\begin{tabular}{llll}
\hline Order & Classification based on content analysis & $\begin{array}{l}\text { Number of } \\
\text { paper }\end{array}$ & Percentage \\
\hline a & $\begin{array}{l}\text { Comparison and evaluation of air quality before and after COVID-19 } \\
\text { outbreak }\end{array}$ & 37 & $14.51 \%$ \\
b & COVID-19 improves environmental quality conditions & 58 & $22.75 \%$ \\
c & Areas with severe air pollution will accelerate the spread of COVID-19 & 54 & $21.18 \%$ \\
d & Contaminated water and food cold chains will accelerate the spread of & 14 & $5.49 \%$ \\
e & COVID-19 & 9 & $3.53 \%$ \\
f & COVID-19 has led to a decline in global energy demand & 8 & $3.14 \%$ \\
g & COVID-19 has led to a decline in global carbon emissions & 29 & $11.37 \%$ \\
h & COVID-19 has caused a lot of medical and health waste & $9.41 \%$ \\
i & The important role of big data and artificial intelligence in environmental & 24 & $8.63 \%$ \\
Total & COVID-19 has changed the way people interact with the environment & 22 & $100.00 \%$ \\
\hline
\end{tabular}


Fig. 3 The bibliographic coupling of articles

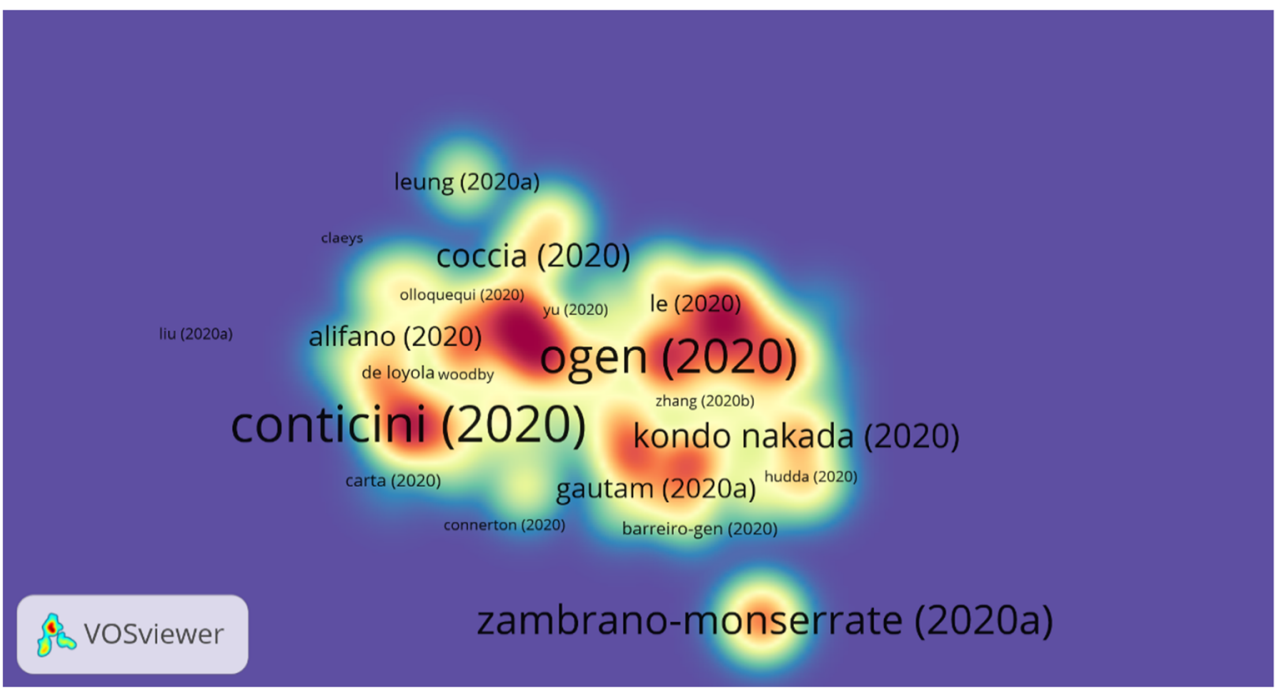

Table 2 lists the total number of citations and average citations of national publications and ranks them from highest to lowest; these are the top ten countries. It can be seen from the table that the total number of publications in China and the total number of citations of publications rank first in the world. In addition, the US publications are ranked second in terms of total citations, followed by India. The total number of citations of Italian publications ranks second, followed by India. The total number of publications and citations of publications in China and India rank in the top three. These countries must not only have an absolute advantage in the number of publications, but also pay more attention to the quality of research on the relationship between COVID-19 and environmental pollution.

As shown in Fig. 6, more than forty countries or regions participated in the research on COVID-19 and the environment. Most of these countries are concentrated in
Eurasia, America, and Europe, which shows that more and more countries are beginning to attach importance to the relationship between COVID-19 and environment and its development. The results show that among all countries or regions that publish related papers, China has the largest number of papers in the world, followed by the USA, India, Italy, and the UK, with betweenness centralities of $0.19,0.28,0.1,0.1$, and 0.26 respectively. It is worth noting that countries with high intermediary centrality, such as Romania (0.87), Australia (0.69), Russia (0.53), and Japan (0.46), also play an important role in the field of research on the relationship between COVID-19 and the environment. The regional distribution characteristics indicate that global research on COVID-19 and the environment is concentrated in developing countries. These data highlight the absolute advantage and international leading position of developing countries in
Fig. 4 The bibliographic coupling of journals

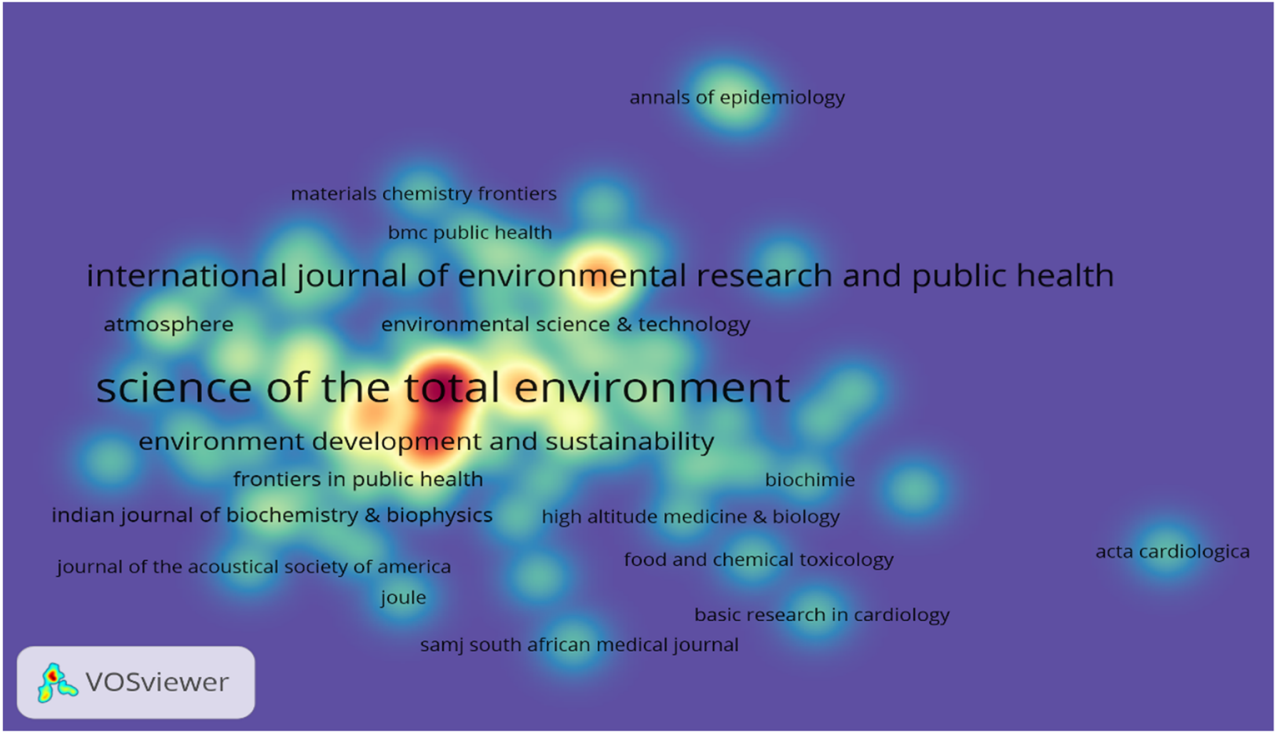


Fig. 5 The bibliographic coupling of authors

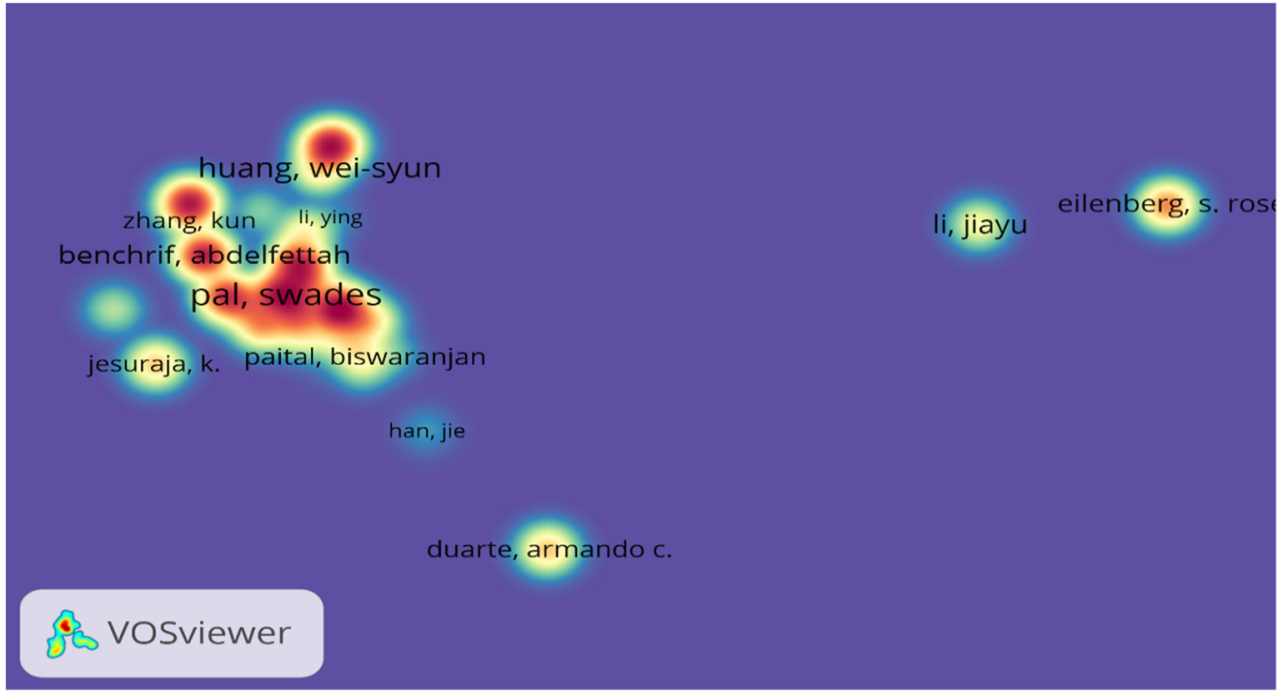

COVID-19 and environmental research, which means that the development of developing countries in this field of research even exceeds that of developed countries such as the USA. China, India, and other countries have the largest number of documents on the relationship between COVID-19 and environmental pollution. Observational data shows that developing countries are the main force in COVID-19 and environmental research in the world. It can be inferred that developing countries will continue to lead global COVID-19 and environmental research and occupy a dominant position in this field.

\section{Developing countries' position in institution of COVID-19-environment research}

This article analyzes the development trend and regional distribution of COVID-19 and environmental research from the perspective of research institutions. In order to visualize the
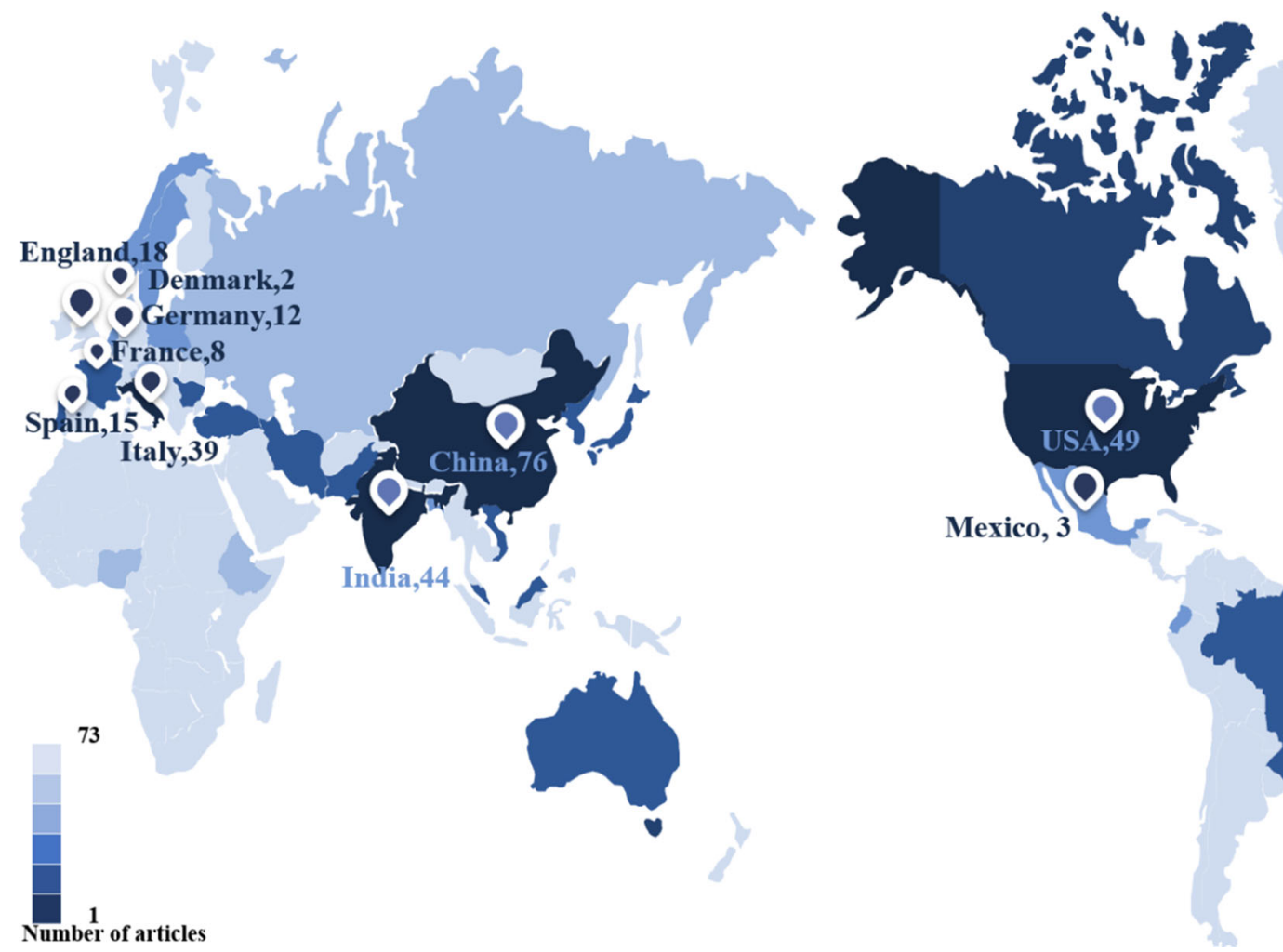

Mexico, 3

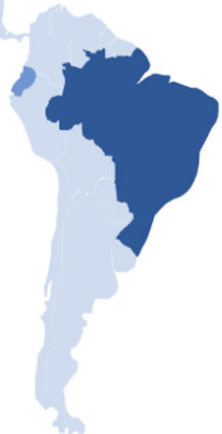

Fig. 6 Total COVID-19-environmental pollution articles of countries 2019-2020 
Table 2 The top 10 countries of the articles on COVID-19-environmental pollution

\begin{tabular}{ccccccccc}
\hline Number & Countries & Articles & Order(AR) & Citations & CPP & Order(CPP) & \\
\hline 1 & China & 76 & 1 & 728 & 9.58 & 5 & \\
2 & Italy & 39 & 4 & 333 & 8.54 & 7 & \\
3 & India & 44 & 3 & 282 & 6.41 & 9 & & \\
4 & USA & 49 & 2 & 232 & 4.73 & 10 & & \\
5 & England & 18 & 5 & 193 & 10.72 & 3 & \\
6 & Spain & 15 & 6 & 131 & 8.73 & 6 & \\
7 & Germany & 12 & 7 & 118 & 9.83 & 4 & \\
8 & Denmark & 2 & 10 & 106 & 53.00 & 1 & & \\
9 & France & 8 & 8 & 64 & 8.00 & 8 & & \\
10 & Mexico & 3 & 9 & 61 & 20.33 & 2 & &
\end{tabular}

research results of various research institutions, this article ranks them according to the total number of papers published by research institutions. Figure 7 and Table 3 show the top 20 research institutions that conduct COVID-19 and environmental research around the world. This article finds that some institutions have relatively few publications, but the average number of citations is relatively high. This shows that although the number of documents published by these institutions is relatively small, each of their documents has received a large number of citations worldwide. These research institutions have conducted more in-depth research on the relationship between COVID-19 and the environment, analyzed the interaction between COVID-19 and the environment from different perspectives, and put forward good suggestions for future research directions.

As shown in Fig. 7, the Chinese Academy of Sciences is the university that conducts the most research on COVID-19 and the environment, and has published 10 articles since the outbreak. Fudan University followed closely behind with 6 articles, ranking second in the world. Shanghai Jiaotong University, ranked third, has also made a lot of efforts in this research field. In addition, it can be seen from Table 3 the top 20 research institutions in the total number of published articles are mainly from China, India, Italy, and the USA, respectively located in Asia, Europe, and North America. These data again support the fact that developing countries dominate COVID-19 and environmental research. This shows that developing countries are at the forefront of the world in COVID19 and environmental research, and may lead the development of global COVID-19 and environmental research in the next decade.

\section{Developing countries' contribution to high-yielding authors of global COVID-19-environment research}

Table 4 shows the highly productive authors in the field of research on the relationship between COVID-19 and environmental since the outbreak of COVID-19. High-yield authors usually master the research hotspots and cutting-edge trends in this field, so they are considered to be an important driving force for the development of the research field. In addition, the nationalities of these highly productive authors are also listed in Table 4. Judging from the total number of papers by highyield authors and their cooperation, the research on COVID19 and the environment is still in the early stage of development, and the research on the relationship between COVID-19 and the environment is not comprehensive and in-depth. It can be seen from Table 4 that Sneha Gautam has published the largest number of papers. During 2019-2020, he published 5 articles on the relationship between COVID-19 and the
Fig. 7 Top 20 research institutions studying COVID-19environmental pollution in the world

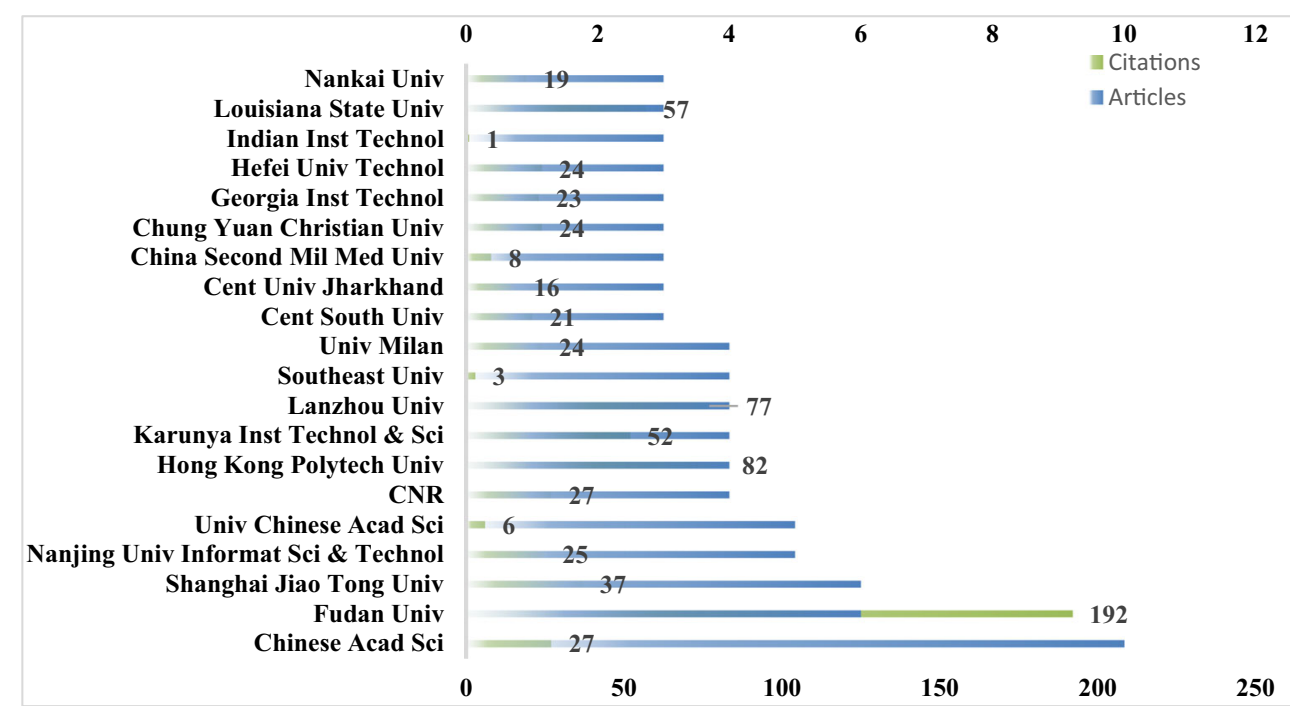


Table 3 List of the world top 20 research institutions studying COVID-19-environmental pollution in the world

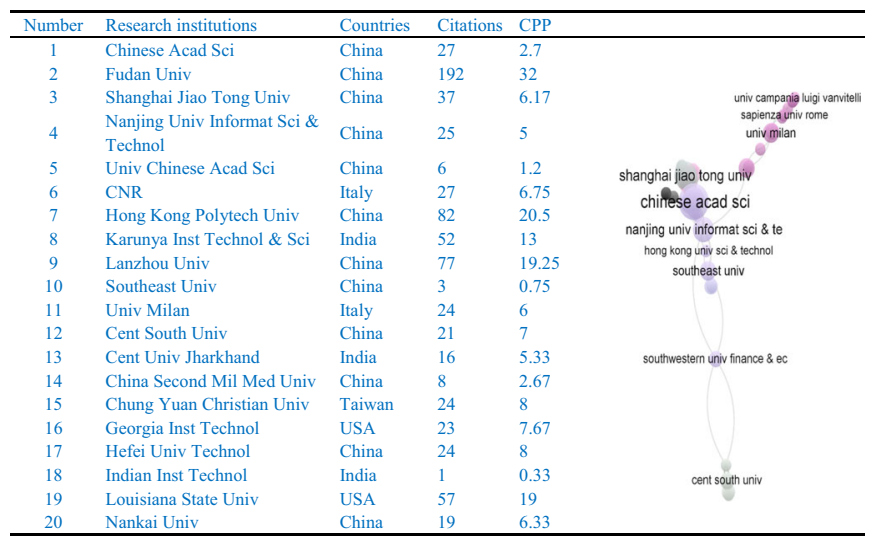

environment. Authors such as Yafen Wang, Weisyun Huang, Shun Wan, Muhammad Farhan Bashir, and Krishna Gopal Ghosh followed closely, and their publications have been highly cited worldwide. Individually, scholars engaged in COVID-19 and environmental research come from different countries, and the top 10 authors are from China, India, and the USA. It is worth noting that among these 10 highly productive authors, 6 are from China and 2 are from India, which means that scholars from developing countries are an integral part of global COVID-19 and environmental research. These findings indicate that the research on COVID-19 and environment in developing countries not only holds an important share in the world in terms of quantity, but also its research institutions and researchers are also in a leading position in the world. In the field of research on the relationship between COVID-19 and the environment, developing countries occupy an important position.

\section{The main reasons}

\section{COVID-19 was first discovered in developing countries}

The COVID-19 pandemic, also known as the coronavirus pandemic, is an ongoing pandemic of coronavirus disease 2019 (COVID-19) caused by severe acute respiratory syndrome coronavirus 2 (SARS-CoV-2), first identified in December 2019 in Wuhan, China. Among the earliest countries to report COVID-19 cases after the outbreak in China were Thailand, Japan, South Korea, Taiwan, and Vietnam, but these countries had successfully controlled the pandemic. As shown in Fig. 8, since the outbreak of COVID-19, it has rapidly spread to most developing countries around the world. Countries where the death toll is gradually increasing are developing countries such as India, Iran, Indonesia, Iraq, and Turkey, with a total of more than 150,000 deaths. The World Health Organization (WHO) announced on March 11, 2020, that "COVID-19" is a global epidemic. Developing countries such as China have taken the lead in adopting a series of prevention and control measures, including closing various public places, postponing and canceling large-scale public events, closing various educational institutions, restricting the movement of people, and public transportation. As of November 2020, there have been more than 60.2 million confirmed cases, of which more than 1.41 million have died due to COVID-19. Since the outbreak of the epidemic, COVID-19 has seriously threatened people's normal lives and touched the core of people's survival. In order to better respond to COVID-19, most research institutions and scholars in developing countries have taken the lead in conducting research on the impact of COVID-19 and its

Table 4 The most active authors in COVID-19-environmental pollution research

\begin{tabular}{|c|c|c|c|c|c|}
\hline Order & Authors & Countries & Articles & Citations & \\
\hline 1 & $\begin{array}{l}\text { SNEHA } \\
\text { GAUTAM }\end{array}$ & India & 5 & 52 & \\
\hline 2 & YAFEN WANG & China & 3 & 24 & \\
\hline 3 & $\begin{array}{l}\text { WEISYUN } \\
\text { HUANG }\end{array}$ & China & 3 & 1 & \\
\hline 4 & $\begin{array}{l}\text { SHUN WAN } \\
\text { MUHAMMAD }\end{array}$ & USA & 3 & 24 & 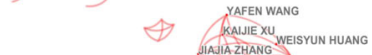 \\
\hline 5 & $\begin{array}{l}\text { FARHAN } \\
\text { BASHIR }\end{array}$ & China & 3 & 21 & 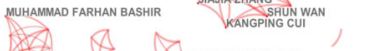 \\
\hline 6 & $\begin{array}{l}\text { KRISHNA } \\
\text { GOPAL GHOSH }\end{array}$ & India & 3 & 48 & $\forall$ SNEHAGAUTAM \\
\hline 7 & KANGPING CUI & China & 3 & 24 & KRISHNA GOPAL GHOSH \\
\hline 8 & KAIJIE XU & China & 3 & 24 & \\
\hline 9 & JIAJIA ZHANG & China & 3 & 24 & $\infty$ \\
\hline 10 & ZIYI LIU & China & 2 & 19 & \\
\hline
\end{tabular}




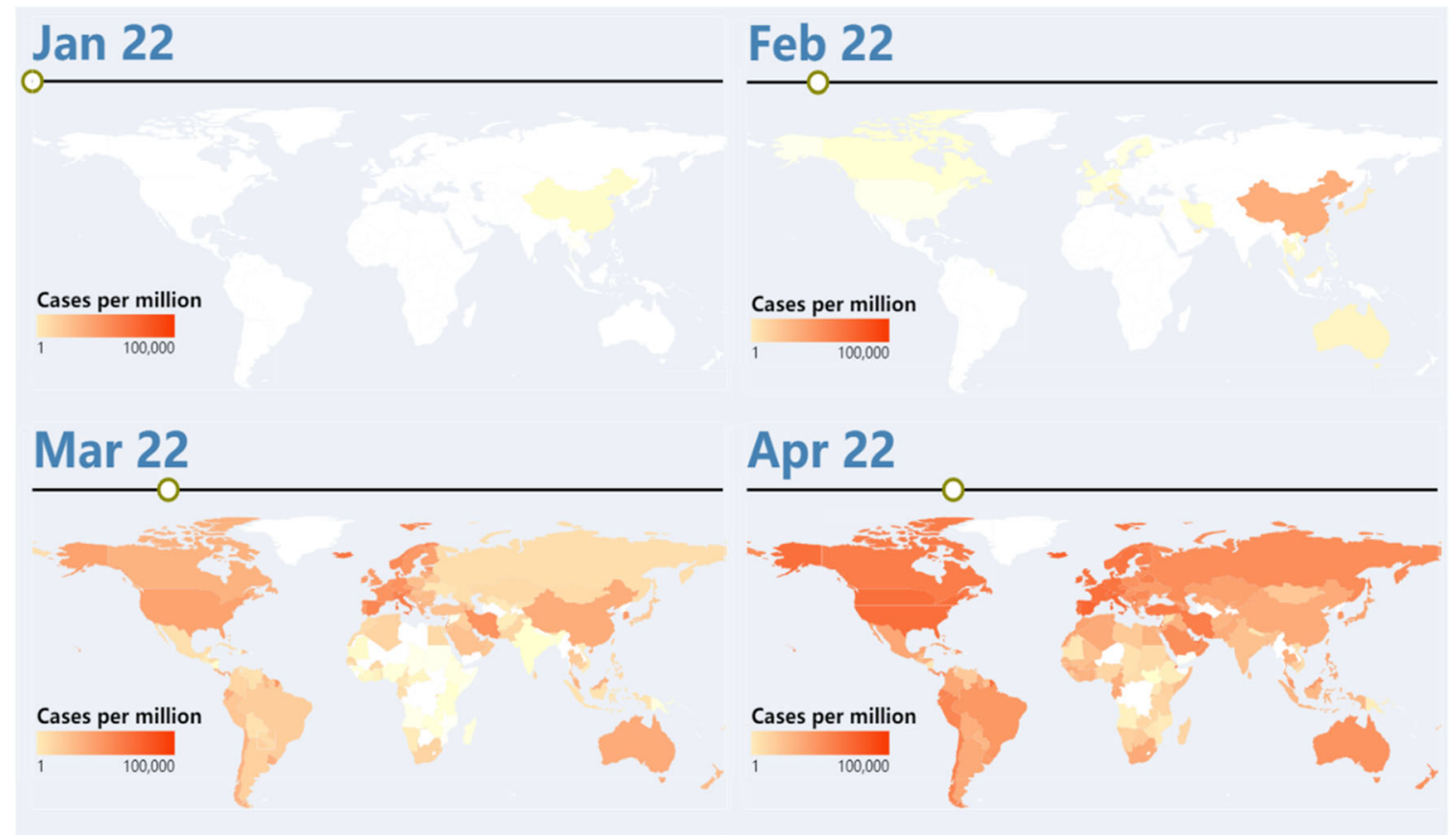

Fig. 8 Interactive timeline map of confirmed cases per million people (source: https://en.wikipedia.org/wiki/COVID-19_pandemic\#History)

driving factors, and found that there is a close relationship between the environment and COVID-19. For example, Chinese research institutions and scholars have begun to summarize and reflect on the characteristics of environmental vulnerability and environmental supervision issues exposed under the impact of COVID-19. After the Chinese New Year holiday in previous years, due to the normal operation of enterprises, coal consumption will show signs of rebound. However, this year is different from previous years. After the normal resumption of work by enterprises and social organizations, coal demand is still sluggish. Through the analysis of domestic environmental quality indicators, they found that the "closed management" measures during the COVID19 outbreak have brought new changes to the environment. The reduction of economic activities and traffic restrictions directly led to changes in China's energy consumption, which further prevented environmental pollution (Wang and $\mathrm{Su}$ 2020b).

\section{Low level of environmental quality}

Most developing countries have low levels of environmental quality. Developing countries such as India are the first to explore the impact of environmental conditions on COVID19 based on their own environmental conditions. It was found that harsh environmental conditions such as poor air quality and serious water pollution would cause the COVID-19 virus to survive longer, and the impact of COVID-19 would worsen. Every year, in many cities in India, sandstorms, volcanic eruptions, and the burning of fossil fuels will reduce the level of environmental quality (Liu and Dong 2021). Figure 9 shows the changes in the concentration of particulate matter in northern India during 2016-2020. During 2016-2019, the concentration of particulate matter in northern India was relatively high, and the air quality was severely polluted, which created certain environmental conditions for the survival of COVID-19, leading to the rapid spread of COVID-19 in India. India is currently the developing country with the largest number of confirmed cases, the number of confirmed cases ranks second in the world, and has always maintained the highest number of daily cases. The Indian government took swift actions and urgent decisions to control the further spread of COVID-19. Ground and satellite observation data analyzed air quality changes and found that the domestic air particulate matter concentration has been greatly reduced after the Indian blockade measures are implemented in 2020 (Adhikari and Yin 2020), as shown in Fig. 9.

\section{Support from the government and related policies}

The COVID-19 pandemic was first discovered in Wuhan, China, in December 2019. The Chinese government quickly implemented corresponding control measures, such as active public health interventions, such as early detection of cases, tracing of contacts, and changes in crowd behavior. With the spread of the COVID-19 pandemic, it first quickly spread to most developing countries around the world. While most developing countries are taking active actions to curb the spread of COVID-19, they have also issued a series of policies and announcements to promote research on COVID-19 in order to completely control the COVID-19 pandemic at the source. 


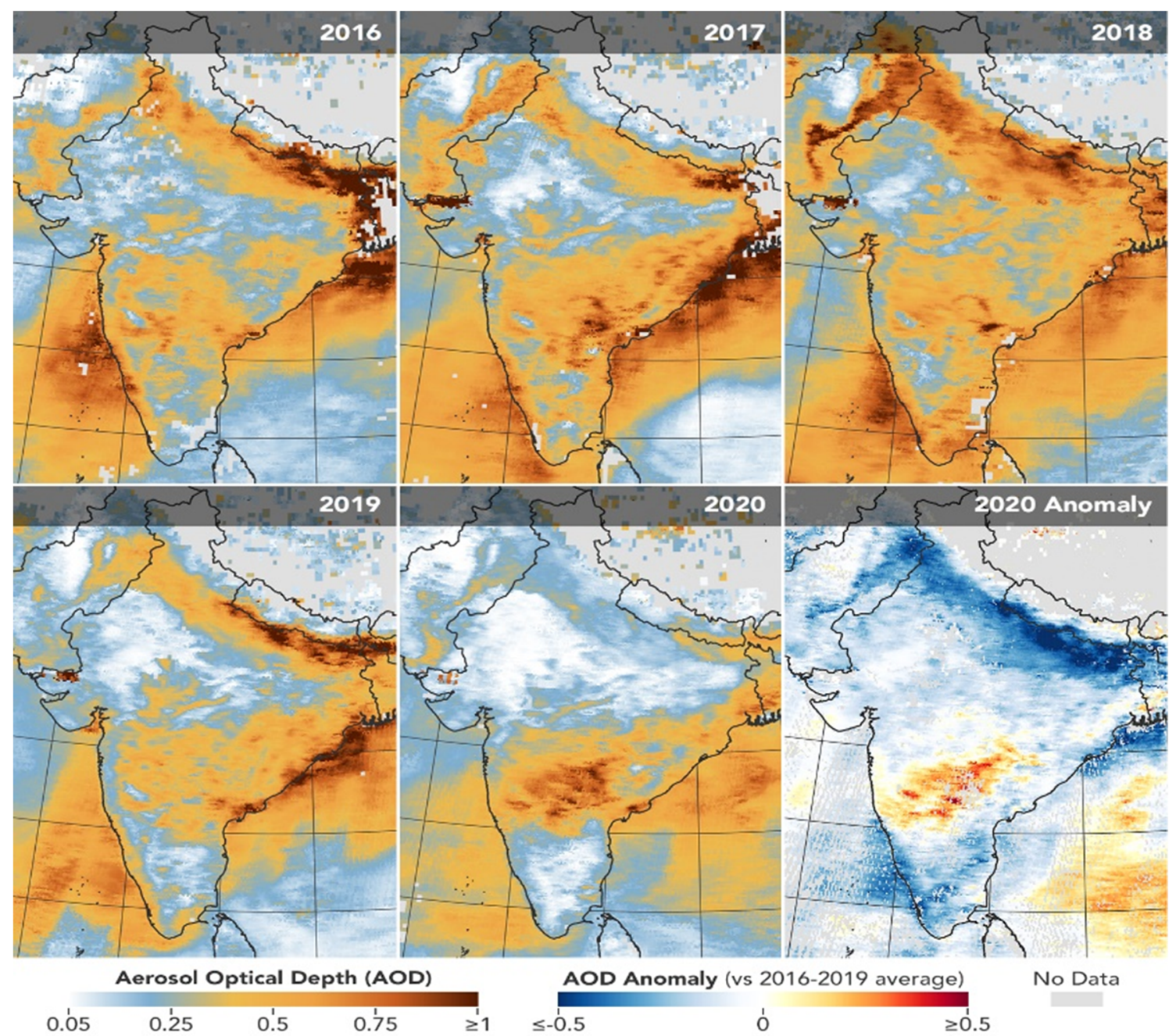

Fig. 9 Airborne particle levels in northern India (source: https://eoimages.gsfc.nasa.gov/images/imagerecords/146000/146596/india_tmo_2016-2020_ lrg.png)

\section{Challenges and solutions}

In order to better understand the relationship between the epidemic and the environment, propose effective solutions to the environmental challenges faced by developing countries under the COVID-19 pandemic, this article will conduct a comprehensive keyword analysis of COVID-19 and environmental research. Keywords contain the core information of an article (Wang and Su 2020a). Keyword analysis can identify valuable information in each document and reveal research hotspots in a particular field (Gao et al. 2020). Due to the suddenness of the epidemic, research on the COVID-19 and environment is still in the development stage. This article used keyword analysis to determine the main hotspots and trends in this research field. Manual or semi-automatic methods were used to standardize keywords with the same meaning into a single keyword to avoid the problem of keyword duplication. Then knowledge graph software was used to analyze the data and only keep the keywords that have appeared at least 5 times. As shown in Fig. 10, the fifteen most common keywords are COVID-19, Air pollution, Lockdown, Air quality, NO2, Particulate matter, PM2.5, China, Environmental pollution, PM10, India, O3, Pandemic, PM2, and Temperature, which confirms the inseparable relationship between COVID-19 and the environment. In order to make the keyword analysis more comprehensive, this article uses the keyword network density map (Fig. 11) to give the relationship between keywords. As can be seen from Fig. 11, the red clusters were dominated by COVID-19, human mobility, infection, temperature, and water. This part of the literature mainly focuses on changes in the public health environment. This reflects that in the early stage of the COVID-19 outbreak, the public health environment on which people depend was first affected; the green clusters were dominated by big data, machine learning, and environment, keywords that belong to many categories, mostly involving the important role of technology in environmental protection. In this part, the keyword "Italy" that represents the country appears. Italy is the country 
Fig. 10 Frequency map of the keyword

COVID-19
Air pollution
Lockdown
Air quality
NO2
Particulate matter
PM2.5
China
Environmental pollution
PM10
India
O3
Pandemic
PM2
Temperature

$100 \%$

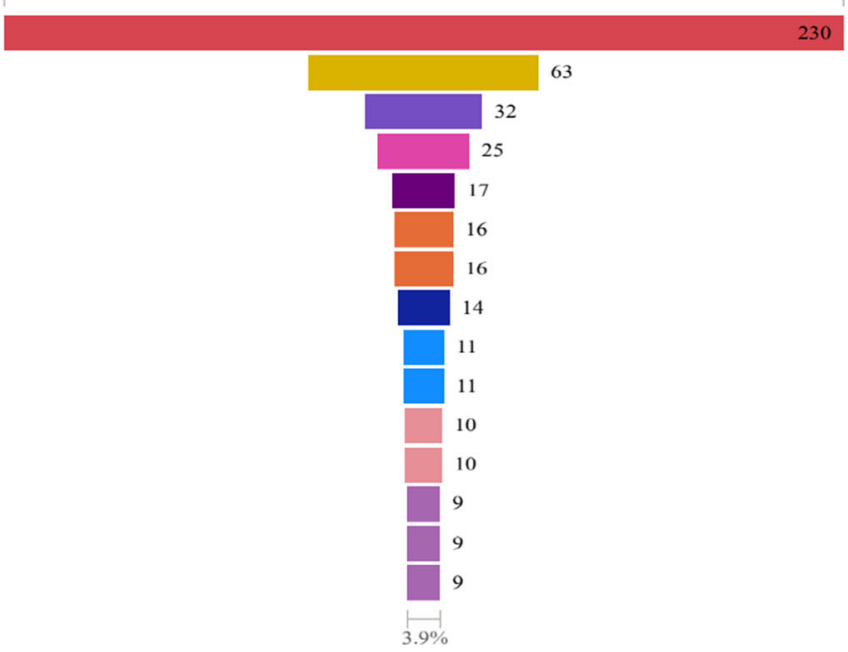

with the most confirmed cases outside of China. On March 8, 2020, the Italian Prime Minister Conte ordered northern Italy to enter a lockdown to control the COVID-19 epidemic spread; most of the blue clusters are keywords related to air quality indicators such as $\mathrm{CO}, \mathrm{CO}_{2}, \mathrm{SO}_{2}, \mathrm{NO}, \mathrm{PM}_{2.5}$, and $\mathrm{PM}_{10}$; the more prominent ones in the yellow cluster are lockdown and traffic emissions, which illustrate the blockade measures adopted by various countries or regions have an impact on energy demand. Therefore, this article divides the research on COVID-19 and the environment into 4 clusters.

\section{Cluster 1: the impact of COVID-19 on the public health environment}

COVID-19 is a sudden major public health security incident, which spreads rapidly around the world and seriously threatened the normal life of human beings. Since the outbreak of COVID-19, most countries and regions around the world have adopted the "lockdown management" to reduce human-to-human contact, and global industrial and commercial economic activities have been greatly reduced. Obviously, COVID-19 prevention and control measures have reduced traffic pressure, air pollution, and improved environmental protection standards (Alsayedahmed 2020). As COVID-19 enters the stage of prevention and control, various countries and regions have increased a lot of medical activities during the prevention and control of COVID-19. The increase in medical activities has led to the generation of a large amount of medical waste, including plastic medical masks and other sanitary waste (Zuo 2020). Disposable plastics are rising again on a global scale, but the unreasonable treatment of disposable plastics has increased environmental pollution.

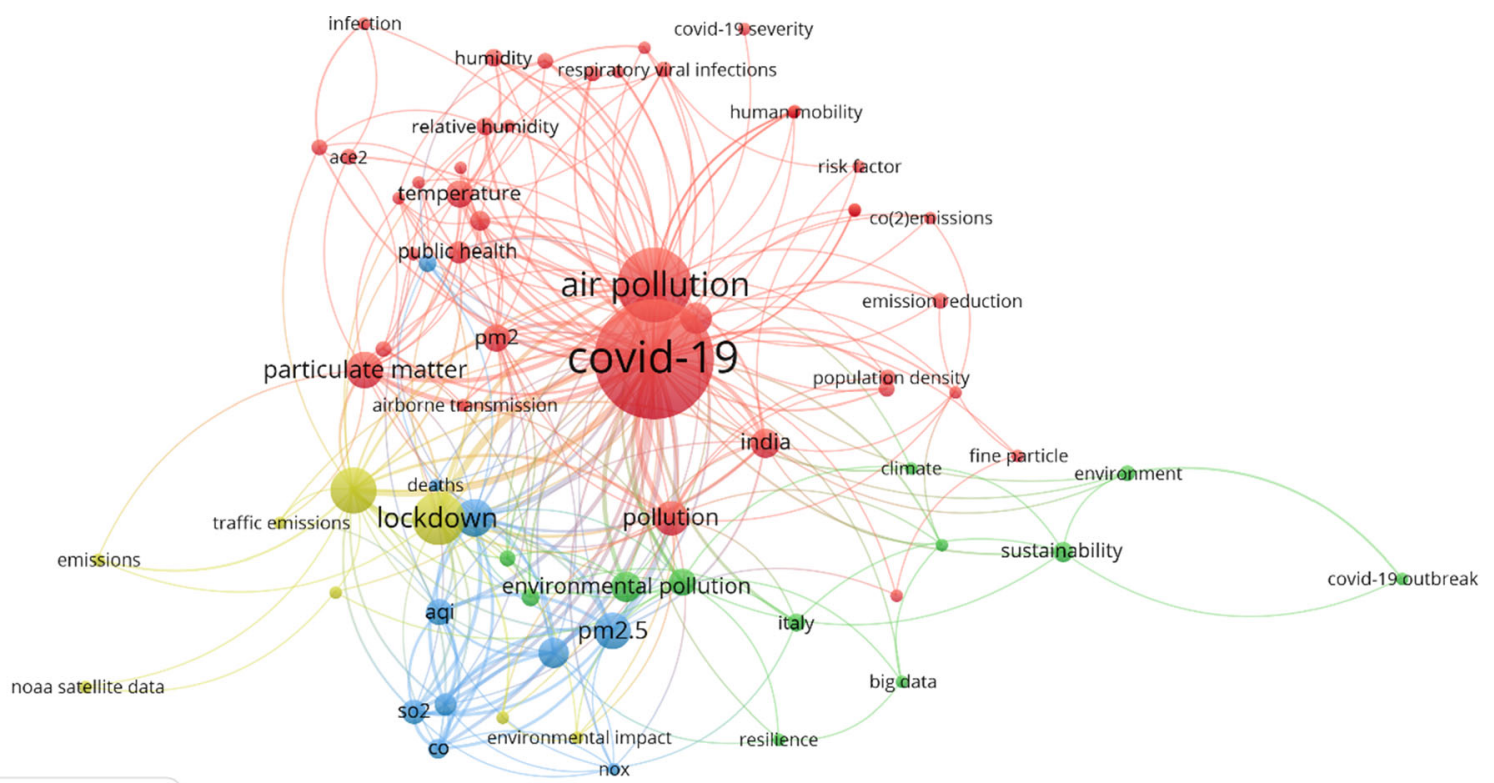

Fig. 11 Network diagram of the keyword analysis 
For example, the load of masks in the oceans of Hong Kong is very large, the fresh water and ocean environments of Africa are full of microplastics, and the Mediterranean is also affected (Aragaw 2020). It is estimated that 129 billion masks and 65 billion gloves are used every month in the world. The unreasonable treatment of disposable plastics and other medical wastes will cause water pollution, soil pollution, and other environmental pollution, which poses a serious threat to public health environment (Prata et al. 2020).

\section{Cluster 2: during the COVID-19 epidemic, the impor- tant role of technology in environmental quality protection}

Big data and advanced technologies play an important role in analyzing relevant indicators during the COVID-19 pandemic (Bragazzi et al. 2020; Wang et al. 2020). For example, big data network detection can provide real-time changes in global air quality indicators since the outbreak, satellite data and a network of 10,000 air quality stations have been used in a survey and it detected a significant decrease in the global concentration of the main components of air pollutants such as nitrogen dioxide, ozone, and fine particulate matter (Venter et al. 2020). The implementation of big data insights can help policymakers, scientists, and health workers better understand the changes in environmental conditions during the COVID19 epidemic, so that they can make more informed decisions and actively respond to COVID-19 while protecting the environment.

During the epidemic prevention and control period, the governments and relevant health departments of various countries have implemented a series of preventive measures, resulting in a large amount of medical waste and disposable products. Unreasonable treatment of these plastic products will cause serious environmental pollution problems. At present, various countries and regions around the world have invested huge scientific research output to support the technological innovation of biosafety and protective equipment, and strive to provide a variety of materials with unique characteristics for the maintenance of biosafety and environmental protection, actively respond to COVID-19 while maintaining good environmental quality (Yu et al. 2020).

\section{Cluster 3: the interaction of COVID-19 and air conditions}

On the one hand, the epidemic of COVID-19 has improved the air quality, water quality, and other environmental conditions to a certain extent. According to meteorological and air quality data obtained by satellites and monitoring stations, the impact of the COVID-19 epidemic on air quality has been discovered (Anil and Alagha 2020). Pollutants in the air include carbon monoxide $(\mathrm{CO})$, sulfur dioxide $\left(\mathrm{SO}_{2}\right)$, nitrogen dioxide $\left(\mathrm{NO}_{2}\right)$, ozone $\left(\mathrm{O}_{3}\right)$, inhalable particulate matter $\left(\mathrm{PM}_{10}\right)$, and other main components. Comparing the air quality index of the unblocked cities and the blocked cities, it was found that the daily air quality index and $\mathrm{PM}_{2.5}$ of the blocked cities dropped by 19.84 points (17\%) and $14.07 \mu \mathrm{g} \mathrm{m}^{-3}$ (17\%), and after the city blockade, the quantity indicators of $\mathrm{CO}, \mathrm{SO}_{2}, \mathrm{NO}_{2}$, and $\mathrm{O}_{3}$ are significantly reduced $(\mathrm{He}, \mathrm{Pan}, \&$ Tanaka). Compared with the concentration of nitric oxide (NO) in the past 7 years, the concentration of NO in the UK this year has decreased by approximately $61 \%$ (Higham et al. 2021). During the COVID-19 virus epidemic, the prevention and control policies of various countries and regions reduced the concentration of air pollutants worldwide, optimized air quality indicators, and improved air quality conditions.

On the other hand, if the environmental conditions and the environmental pollution in a country or region are severe, the country or region will be more affected by COVID-19. On the other hand, if the environmental conditions and the environmental pollution in a country or region are severe, the country or region will be more affected by COVID-19 (Bontempi et al. 2020). According to the survey data, air quality data and COVID-19 case data show a positive correlation. Seriously polluted areas will create a more favorable environment for the spread of the virus, further affecting the body's immune function and metabolism, thereby increasing the mortality rate of COVID-19. The improvement of air quality is beneficial to the survival of COVID-19 patients (Adhikari and Yin 2020; Bianconi et al. 2020; Cai et al. 2020; Chakraborty et al. 2020; Chang et al. 2020; Frontera et al. 2020)

\section{Cluster 4: the impact of COVID-19 on energy}

Since the outbreak of COVID-19, most countries and regions around the world have taken measures to prevent the further spread of COVID-19 and prevent it from reaching the core of people's lives. Most countries or regions restrict people's travel, cancel a large number of public activities, and close all nonessential public places, resulting in a large number of manufacturers, suppliers, and retailers unable to operate normally, and a large reduction in economic activities and new companies forced closed. Due to the substantial reduction in economic activities and transportation activities, the consumption of non-renewable energy such as coal and oil have been greatly reduced. Due to the outbreak of the epidemic, the demand for coal, oil, and other energy sources in various countries and regions around the world have dropped sharply. The global renewable energy supply chain has also received a shocking impact. The spread of COVID-19 has caused a wind power plant in North Dakota of the USA to close its facilities; certain areas in some European countries have also stopped the production and assembly of wind turbine blade factories; most workers in the solar energy industry have also been forced to dismissal; the epidemic has indeed had a huge impact on the 
development of renewable energy (Eroglu 2020). It can be seen that the outbreak of COVID-19 has not only drastically reduced the consumption of non-renewable energy such as coal and oil, but also has led to a sharp drop in the demand for renewable energy in most countries and regions around the world.

Carbon dioxide emissions are affected by multiple factors. The first is the constraint of energy demand. COVID-19 broke out at the end of 2019 and began to spread rapidly to South Korea, Japan, Europe, and the USA at the beginning of 2020. Various countries and regions have adopted closed policies during the COVID-19 epidemic that has led to a forced reduction in energy demand, which has an impact on carbon dioxide emissions. The International Energy Agency estimates based on data that the total energy consumption in 2020 will be 4 $6 \%$ less than the total energy consumption in 2019. The final total energy consumption will depend on the speed of economic recovery after the epidemic (Table 5). This would lead to the lowest level of global GHG emissions since 2010 with a decrease of $8 \%$ with respect to 2019 (Malliet et al. 2020)

Based on the above analysis results, the environmental challenges facing developing countries should take into account the following aspects:

(1) There is a two-way impact between the COVID-19 epidemic and the environment. On the one hand, the prevention and control measures related to the COVID-19 epidemic have improved public health conditions and reduced air pollution while raising environmental protection standards. However, unreasonable treatment of medical and health waste will have a negative impact on the sustainable development of the environment. On the other hand, areas with poor environmental quality will promote the spread of COVID-19.

(2) With the advent of the information age, advanced technologies such as big data, artificial intelligence, and blockchain have penetrated into all aspects of people's lives. Application of big data and artificial intelligence played an important role in improving environmental quality during the COVID-19 pandemic.

(3) Due to the outbreak of the epidemic, the demand for energy such as coal and oil has dropped sharply in various countries and regions around the world, and carbon emissions have been greatly reduced.

Therefore, this article looks forward to the development of the global environment during the epidemic and puts forward effective countermeasures against the environmental challenges facing developing countries in the context of the COVID-19 epidemic:

(1) The governments of developing countries should formulate relevant guidance policies based on the actual treatment of local medical and health waste, increase the implementation of safeguards such as providing sanitation facilities in public places, and create good environmental quality conditions. Moreover, governments of various countries and regions should learn from the epidemic and formulate relevant policies and environmental protection standards to maintain normal economic operations while maintaining good environmental conditions to reduce the possibility of an outbreak (Shao et al. 2020; Tian et al. 2020). In addition, developing countries can fully consider the impact of the interaction of other factors on COVID-19 and environmental research, and provide a stronger theoretical basis for the prevention and control of future epidemics and the sustainable development of the environment (Dong and Liu 2020; Zhang et al. 2020).

(2) To get rid of the crisis caused by COVID-19 epidemic, international exchanges and cooperation are essential (Wang and Zhang 2021). Different countries actively respond to COVID-19 according to their own national conditions. Compared with some developing countries, some developed countries have also been severely affected by the COVID-19 pandemic, such as European countries and the USA. Although many countries have adopted some preventive and control measures, these measures may not really play a role in delaying the spread of the epidemic. Developing countries and developed countries need to exchange and share knowledge, learn from each other, and complement each other's advantages. For a long time, developed countries have had technological advantages in big data and artificial intelligence. Developing countries can take advantage of the technological advantages of developed countries in the fields of artificial intelligence and big data to help policymakers, scientists, and health workers better understand the changes in environmental conditions during the COVID-19 epidemic. Developed countries can learn from the experience and resources of developing countries on COVID-19 and environmental research to form a stable and global scientific research cooperation force to jointly respond to the challenges of the COVID-19 epidemic and promote the sustainable development of the environment.

(3) Developing countries should learn from the COVID-19 epidemic, further adjust and improve their energy consumption structure, and pay more attention to the policy and environment for the development of renewable energy (Wang and Wang 2020). Decisionmakers should pay more attention to formulating policies with multilateral environmental constraints while paying attention to R\&D investment and introducing strict environmental policies to promote the sustainable development of energy and promote further energy transformation (Ai et al. 2020; Li et al. 2021). 
Table 5 Summary of articles in the four clusters

Author(s) Purpose Country Key findings

Cluster 1: the impact of COVID-19 on the public health environment

Alsayedahmed To explore the impact of protective measures against the (2020) COVID-19 pandemic on family and environmental health

Saudi I. In fact, the combination of restriction and Arabia protection measures is the most effective way to contain the spread of COVID-19.

II. COVID-19 protection measures not only improve the quality of the social environment, but also create healthier climatic conditions.

Aragaw (2020) To study the huge impact of the pollution of microplastics such as Ethiopia masks on the aquatic biota and the entire environment

The productivity of surgical masks used to control the spread of COVID-19 is increasing. Surgical masks eventually pose a threat to the environment as microplastic pollution.

Prata et al. To assess the pollution and impact of plastic caused by COVID-19 Portugal, (2020) Canada

I. During the COVID-19 pandemic, an estimated 129 billion masks and 65 billion gloves are used every month globally, posing a threat to the public health environment.

II. While not underestimating the importance of plastics in the spread of COVID-19, it is necessary to evaluate alternatives to reduce personal protective equipment and increase public awareness of the proper use and disposal of plastics.

Cluster 2: during the COVID-19 epidemic, the important role of technology in environmental quality protection

Bragazzi et al. To outline the potential applications of artificial intelligence and USA, big data in the global governance of COVID-19

Taiwan

Artificial intelligence and big data can process a large amount of data from public health surveillance in real time, which can detect the trend of COVID-19, allowing government agencies and relevant departments to quickly adjust prevention measures.

Venter et al. To detect and evaluate changes in global environmental quality (2020) indicators during the COVID-19 pandemic

Norway,

Germa-

ny

After using satellite data and air quality stations to detect ground indicators, it was found that the concentration of the main components of air pollutants such as nitrogen dioxide, ozone, and fine particulate matter was significantly reduced.

Yu et al. To use new technologies and new materials to respond to the China (2020) serious safety and health incident of COVID-19

Wang et al. To analyze Taiwan's application of big data and information (2020) technology to prevent epidemics and provide suggestions for the prevention and treatment of COVID-19 globally

Cluster 3: the interaction of COVID-19 and air conditions

Anil and

Alagha

(2020)

Based on the meteorological and air quality data obtained by the Saudi eight monitoring stations in the eastern part of KSA, to study the Arabia possible impact of lockdown measures on air quality during COVID-19

He et al
Using the difference-in-difference model to infer the causal relationship between COVID-19 and the air quality index

China

(2020)
Canada,

Italy,

USA,

Iran
The outbreak of COVID-19 has made people realize that it is necessary to use new science and technology to develop effective drugs and vaccines, quickly and in real time perform virus detection, and strengthen protective equipment and transportation equipment.

The Taiwan government uses big data and artificial intelligence technology to establish a public health response mechanism to notify the public of health information every day and provide timely, accurate, and transparent information about COVID-19.

I. The concentration of $\mathrm{PM}_{10}, \mathrm{CO}$, and $\mathrm{SO}_{2}$ in the eastern provinces has decreased greatly, while the concentration of ozone has shown an upward trend.

II. Closure measures during the COVID-19 pandemic improved air quality.

The city blockade led to a substantial improvement in air quality, and the air quality index of the blocked city dropped by 19.84 points. The air quality of unblocked cities has also improved due to other types of anti-virus measures. The air quality index of these cities has dropped by 6.34 points. 
Table 5 (continued)

\begin{tabular}{|c|c|c|c|}
\hline Author(s) & Purpose & Country & Key findings \\
\hline $\begin{array}{l}\text { Higham et al. } \\
\text { (2021) }\end{array}$ & $\begin{array}{l}\text { To study how the lockdown measures during COVID-19 affect } \\
\text { the air quality in the UK }\end{array}$ & UK & $\begin{array}{l}\text { The level of nitrogen oxides in the country has } \\
\text { dropped sharply, but the levels of ozone and sulfur } \\
\text { dioxide in the country have increased. }\end{array}$ \\
\hline $\begin{array}{l}\text { Adhikari and } \\
\text { Yin (2020) }\end{array}$ & $\begin{array}{l}\text { To study the relationship between the concentration of ozone and } \\
\mathrm{PM}_{2.5} \text { and the COVID-19 pandemic }\end{array}$ & USA & $\begin{array}{l}\text { Short-term exposure to ozone and other } \\
\text { meteorological factors can affect the spread of } \\
\text { COVID-19 and the onset of disease. }\end{array}$ \\
\hline $\begin{array}{l}\text { Bianconi et al. } \\
\text { (2020) }\end{array}$ & $\begin{array}{l}\text { To investigate whether the number of COVID-19 cases and mor- } \\
\text { tality in Italy are related to exposure to fine and coarse particles }\end{array}$ & $\begin{array}{l}\text { Italy, } \\
\text { Poland }\end{array}$ & $\begin{array}{l}\text { I. A heterogeneous distribution of COVID-19 } \\
\text { cases/deaths and particulate matter exposure was } \\
\text { observed in Italy, with the highest numbers in } \\
\text { Northern Italy regions and provinces. } \\
\text { II. Exposure to } \text { PM }_{2.5} \text { and } \text { PM }_{10} \text { is associated with } \\
\text { COVID- } 19 \text { cases and deaths, suggesting that par- } \\
\text { ticulate matter pollution may play a role in the } \\
\text { COVID-19 outbreak. }\end{array}$ \\
\hline $\begin{array}{l}\text { Chakraborty } \\
\text { et al. (2020) }\end{array}$ & $\begin{array}{l}\text { To explore the impact of COVID-19 on the population in areas } \\
\text { with different levels of pollution }\end{array}$ & India & $\begin{array}{l}\text { I. The concentration of nitrogen dioxide in the } \\
\text { atmosphere has a strong positive correlation with } \\
\text { the mortality of COVID- } 19 \text {. } \\
\text { II. One of the main sources of nitrogen dioxide in the } \\
\text { atmosphere is the burning of fossil fuels, so people } \\
\text { who are frequently exposed to motor vehicle } \\
\text { exhaust are at higher risk in the COVID-19 pan- } \\
\text { demic. }\end{array}$ \\
\hline $\begin{array}{l}\text { Frontera et al. } \\
\text { (2020) }\end{array}$ & $\begin{array}{l}\text { To analyze the relationship between the concentration of air } \\
\text { pollutants }\left(\mathrm{PM}_{2.5} \text { and } \mathrm{NO}_{2}\right) \text { and the COVID- } 19 \text { outbreak, in- } \\
\text { cluding the transmission rate, the number of patients, the se- } \\
\text { verity of the illness, and the number of deaths }\end{array}$ & $\begin{array}{l}\text { Italy, } \\
\text { France }\end{array}$ & $\begin{array}{l}\text { I. Chronic exposure to } \mathrm{PM}_{2.5} \text { causes alveolar ACE- } 2 \\
\text { receptor overexpression. This may increase viral } \\
\text { load in patients exposed to pollutants in turn de- } \\
\text { pleting ACE-2 receptors and impairing host de- } \\
\text { fenses. } \\
\text { II. High atmospheric } \mathrm{NO}_{2} \text { may provide a second hit } \\
\text { causing a severe form of SARS-CoV-2 in } \\
\text { ACE-2-depleted lungs resulting in a worse out- } \\
\text { come. }\end{array}$ \\
\hline \multicolumn{4}{|c|}{ Cluster 4: the impact of COVID-19 on energy } \\
\hline Eroglu (2020) & $\begin{array}{l}\text { To discuss the effects of COVID-19 outbreak in terms of the } \\
\text { environment and renewable energy sector in the literature were } \\
\text { examined in detail }\end{array}$ & Turkey & $\begin{array}{l}\text { The outbreak caused very serious problems in the } \\
\text { renewable energy sector; countries need to } \\
\text { demonstrate very serious clean energy incentives. }\end{array}$ \\
\hline $\begin{array}{l}\text { Malliet et al. } \\
\quad(2020)\end{array}$ & $\begin{array}{l}\text { To provide a quantitative assessment of the economic and } \\
\text { environmental impacts of the lockdown measures in the short } \\
\text { and long term }\end{array}$ & $\begin{array}{l}\text { France, } \\
\text { UK }\end{array}$ & $\begin{array}{l}\text { The lockdown has led to a significant decrease in } \\
\text { economic output of } 5 \% \text { of GDP, but a positive } \\
\text { environmental impact with a } 6.6 \% \text { reduction in } \\
\mathrm{CO}_{2} \text { emissions in } 2020 \text {. }\end{array}$ \\
\hline
\end{tabular}

\section{Conclusions}

This article collects papers on COVID-19 and the environment included in the WOS database, aims to explore the research status quo, and assesses the environmental challenges facing developing countries. This article systematically analyzes and summarizes the global development status of COVID-19 epidemic and environmental research, and analyzes the contribution of developing countries in COVID-19 epidemic and environmental research from the perspective of total literature, research institutions, and high-yield authors. This article draws the following conclusions:

The COVID-19 pandemic, also known as the coronavirus pandemic, is the 2019 coronavirus disease (COVID-19) pandemic caused by the severe acute respiratory syndrome coronavirus 2 (SARS-CoV-2). It is an unexpected major public health security incident, and COVID-19 has the characteristics of a wide range of infections, fast spreading speed, and difficult prevention. It broke out and spread rapidly in multiple locations around the world, causing a great impact on global environmental conditions and environmental supervision, seriously touched the core of human survival. The environmental sustainability in the context of the pandemic has aroused widespread concern in the academic community. At the national level, most research institutions and scholars in developing countries have taken the lead in researching the impact of COVID-19 and its driving factors. The number of papers published in developing countries ranks among the world's leaders. As the most productive research institutions and authors in the world, research institutions and researchers in 
developing countries are an important part of global COVID19 and environmental research. The above results indicate that the research on COVID-19 and the environment in developing countries not only accounts for an important share in the number of papers, but also its research institutions and researchers also play an important role in the global research on COVID19 and the environment. In summary, from the perspective of the number of papers, research institutions, and researchers, developing countries have made great contributions to the study of COVID-19 and the environment.

This article further prospects the development of the global environment during the epidemic and puts forward corresponding countermeasures and suggestions for the environmental challenges facing developing countries in the context of the COVID-19 epidemic. It turns out that the impact of COVID-19 and the environment was bidirectional. Energy has suffered a huge impact, and advanced technologies such as artificial intelligence and big data can help decisionmakers, scientists, and health workers better understand the changes in environmental conditions during the COVID-19 epidemic, and play an important role. Therefore, governments in developing countries should learn from the epidemic and formulate relevant policies to maintain normal economic operations while maintaining good environmental quality conditions to reduce the possibility of an outbreak. In addition, policymakers should further adjust and improve the energy consumption structure, pay more attention to formulating policies with multilateral environmental constraints while strengthening R\&D investment, and introduce strict environmental policies to promote the sustainable development of energy. In addition, developing countries and developed countries need to exchange and share knowledge, and learn from each other. Developing countries can take the technological advantages of developed countries in the fields of artificial intelligence and big data, and developed countries can learn from the experience and resources of developing countries on COVID-19 and environmental research to form a stable and global scientific research cooperation force, so as to jointly respond to the challenges of the COVID-19 epidemic and build a greener, environmentally sustainable world.

These findings help determine the relationship between the COVID-19 pandemic and environment, as well as the research capabilities of developing countries on COVID-19 and environment, and indicate the environmental problems faced during COVID-19. There is a lack of systematic research on the COVID-19 pandemic and environment in academia. This article provides a macro-system analysis of the global COVID-19 pandemic and environmental research, comprehensively assessing the research capabilities of COVID-19 and the environment in developing countries, and policy recommendations for developing countries to meet the environmental challenges induced by the pandemic were offered. In addition, we recommend that future research further investigate the impact of big data and artificial intelligence on the environment during the COVID-19 pandemic and enrich the selected database.

Author contribution QW: conceptualization, methodology, software, data curation, writing - original draft preparation, supervision, writingreviewing and editing; CZ: methodology, software, investigation, writing — original draft, writing — reviewing and editing

Funding This work is funded by the National Natural Science Foundation of China (Grant No. 71874203), Humanities and Social Science Fund of Ministry of Education of China (Grant No. 18YJA790081), and Natural Science Foundation of Shandong Province, China (Grant No. ZR2018MG016).

Data availability The datasets used and/or analyzed during the current study are available from the corresponding author on reasonable request.

\section{Declarations}

Ethics approval and consent to participate Not applicable.

Consent for publication Not applicable.

Competing interests The authors declare no competing interests.

\section{References}

Adhikari A, Yin JJ (2020) Short-term effects of ambient ozone, PM2.5, and meteorological factors on COVID-19 confirmed cases and deaths in Queens, New York. Int J Environ Res Public Health 17(11). https://doi.org/10.3390/ijerph17114047

Ahmed AT, Ghanem AS (2020) A statistical study for impacts of environmental conditions on the rapid spread of new corona virus. Int $\mathrm{J}$ Environ Sci Technol 17(10):4343-4352. https://doi.org/10.1007/ s13762-020-02858-y

Ai H, Hu S, Li K, Shao S (2020) Environmental regulation, total factor productivity, and enterprise duration: evidence from China. Bus Strateg Environ 29(6):2284-2296. https://doi.org/10.1002/bse.2502

Albort-Morant G, Ribeiro-Soriano D (2016) A bibliometric analysis of international impact of business incubators. J Bus Res 69(5):17751779. https://doi.org/10.1016/j.jbusres.2015.10.054

Alsayedahmed HH (2020) COVID-19 pandemic's precautionary measures had hit the reset button of the quality of life at different aspects. J Infect Develop Count 14(8):812-816. https://doi.org/10.3855/jidc. 12943

Anil I, Alagha O (2020) The impact of COVID-19 lockdown on the air quality of Eastern Province, Saudi Arabia. Air Qual Atmos Health 14:117-128. https://doi.org/10.1007/s11869-020-00918-3

Aragaw TA (2020) Surgical face masks as a potential source for microplastic pollution in the COVID-19 scenario. Mar Pollut Bull 159:111517. https://doi.org/10.1016/j.marpolbul.2020.111517

Aria M, Cuccurullo C (2017) bibliometrix: an R-tool for comprehensive science mapping analysis. J Inform 11(4):959-975. https://doi.org/ 10.1016/j.joi.2017.08.007

Arora S, Bhaukhandi KD, Mishra PK (2020) Coronavirus lockdown helped the environment to bounce back. Sci Total Environ 742: 742. https://doi.org/10.1016/j.scitotenv.2020.140573 
Bashir MF, Ma BJ, Shahzad L (2020) A brief review of socio-economic and environmental impact of Covid-19. Air Qual Atmos Health 13: 1403-1409. https://doi.org/10.1007/s11869-020-00894-8

Bhowmick GD, Dhar D, Nath D, Ghangrekar MM, Banerjee R, Das S, Chatterjee J (2020) Coronavirus disease 2019 (COVID-19) outbreak: some serious consequences with urban and rural water cycle. Npj Clean Water 3(1). https://doi.org/10.1038/s41545-020-0079-1

Bianconi V, Bronzo P, Banach M, Sahebkar A, Mannarino MR, Pirro M (2020) Particulate matter pollution and the COVID-19 outbreak: results from Italian regions and provinces. Arch Med Sci 16(5): 985-992. https://doi.org/10.5114/aoms.2020.95336

Bontempi E, Vergalli S, Squazzoni F (2020) Understanding COVID-19 diffusion requires an interdisciplinary, multi-dimensional approach. Environ Res 188:109814. https://doi.org/10.1016/j.envres.2020. 109814

Bragazzi NL, Dai HJ, Damiani G, Behzadifar M, Martini M, Wu JH (2020) How big data and artificial intelligence can help better manage the COVID-19 pandemic. Int J Environ Res Public Health 17(9). https://doi.org/10.3390/ijerph17093176

Cai YW, Huang TL, Liu X, Xu GS (2020) The effects of "Fangcang, Huoshenshan, and Leishenshan" hospitals and environmental factors on the mortality of COVID-19. Peerj 8:e9578. https://doi.org/ $10.7717 /$ peerj. 9578

Carducci A, Federigi I, Liu DS, Thompson JR, Verani M (2020) Making waves: coronavirus detection, presence and persistence in the water environment: state of the art and knowledge needs for public health. Water Res 179:115907. https://doi.org/10.1016/j.watres.2020. 115907

Chakraborty P, Jayachandran S, Padalkar P, Sitlhou L, Chakraborty S, Kar R, Bhaumik S, Srivastava M (2020) Exposure to nitrogen dioxide (NO2) from vehicular emission could increase the COVID-19 pandemic fatality in India: a perspective. Bull Environ Contam Toxicol 105(2):198-204. https://doi.org/10.1007/s00128-02002937-3

Chang YH, Huang RJ, Ge XL, Huang XP, Hu JL, Duan YS et al (2020) Puzzling haze events in China during the coronavirus (COVID-19) shutdown. Geophys Res Lett 47(12). https://doi.org/10.1029/ $2020 \mathrm{gl} 1088533$

Cheng M, Edwards D, Darcy S, Redfern K (2018) A tri-method approach to a review of adventure tourism literature: bibliometric analysis, content analysis, and a quantitative systematic literature review. J Hosp Tour Res

Chin A, Simon GL, Anthamatten P, Kelsey KC, Crawford BR, Weaver AJ (2020) Pandemics and the future of human-landscape interactions. Anthropocene 31:100256. https://doi.org/10.1016/j.ancene. 2020.100256

Coccia M (2020) Factors determining the diffusion of COVID-19 and suggested strategy to prevent future accelerated viral infectivity similar to COVID. Sci Total Environ 729. https://doi.org/10.1016/j. scitotenv.2020.138474

Dong F, Liu Y (2020) Policy evolution and effect evaluation of newenergy vehicle industry in China. Res Policy 67:101655. https:// doi.org/10.1016/j.resourpol.2020.101655

Editorial (2020) Transition from pandemic. Nat Sustain 3(5):345-345. https://doi.org/10.1038/s41893-020-0546-1

Eroglu H (2020) Effects of Covid-19 outbreak on environment and renewable energy sector. Environ Dev Sustain. https://doi.org/10. 1007/s10668-020-00837-4

Frontera A, Cianfanelli L, Vlachos K, Landoni G, Cremona G (2020) Severe air pollution links to higher mortality in COVID-19 patients: the "double-hit" hypothesis. J Infect 81(2):255-259. https://doi.org/ 10.1016/j.jinf.2020.05.031

Gao H, Ding X-H, Wu S (2020) Exploring the domain of open innovation: bibliometric and content analyses. J Clean Prod 275:122580. https://doi.org/10.1016/j.jclepro.2020.122580
Goh KH, See KF (2020) Twenty years of water utility benchmarking: a bibliometric analysis of emerging interest in water research and collaboration. J Clean Prod 124711:124711. https://doi.org/10. 1016/j.jclepro.2020.124711

Hache E, Palle A (2019) Renewable energy source integration into power networks, research trends and policy implications: a bibliometric and research actors survey analysis. Energy Policy 124:23-35. https://doi.org/10.1016/j.enpol.2018.09.036

Han J, Zhang X, He SS, Jia PQ (2020) Can the coronavirus disease be transmitted from food? A review of evidence, risks, policies and knowledge gaps. Environ Chem Lett 19:5-16. https://doi.org/10. 1007/s10311-020-01101-x

He GJ, Pan YH, Tanaka T (2020) The short-term impacts of COVID-19 lockdown on urban air pollution in China. Nat Sustain 3:10051011. https://doi.org/10.1038/s41893-020-0581-y

Higham JE, Ramirez CA, Green MA, Morse AP (2021) UK COVID-19 lockdown: 100 days of air pollution reduction? Air Qual Atmos Health 14:325-332. https://doi.org/10.1007/s11869-020-00937-0

Hu W, Li C-H, Ye C, Wang J, Wei W-W, Deng Y (2019) Research progress on ecological models in the field of water eutrophication: CiteSpace analysis based on data from the ISI web of science database. Ecol Model 410:108779. https://doi.org/10.1016/j.ecolmodel. 2019.108779

Kim J, Hastak M (2018) Social network analysis: characteristics of online social networks after a disaster. Int J Inf Manag 38(1):86-96. https:// doi.org/10.1016/j.ijinfomgt.2017.08.003

Krishnamurthy S (2020) The future of business education: a commentary in the shadow of the Covid-19 pandemic. J Bus Res 117:1-5. https:// doi.org/10.1016/j.jbusres.2020.05.034

Lee SM, Trimi S (2021) Convergence innovation in the digital age and in the COVID-19 pandemic crisis. J Bus Res 123:14-22. https://doi. org/10.1016/j.jbusres.2020.09.041

Li G, Lu S, Shao S, Yang L, Zhang K (2021) Do environmental regulations hamper small enterprises' market entry? Evidence from China. Bus Strateg Environ 30(1):252-266. https://doi.org/10.1002/bse. 2619

Liao HC, Tang M, Luo L, Li CY, Chiclana F, Zeng XJ (2018) A bibliometric analysis and visualization of medical big data research. Sustainability 10(1). https://doi.org/10.3390/su10010166

Liu XJ, Wang MM, Fu HL (2020) Visualized analysis of knowledge development in green building based on bibliographic data mining. J Supercomput 76(5):3266-3282. https://doi.org/10.1007/s11227$018-2543-y$

Liu Y, Dong F (2021) Haze pollution and corruption: a perspective of mediating and moderating roles. J Clean Prod 279:123550. https:// doi.org/10.1016/j.jclepro.2020.123550

Lopes APVBV, de Carvalho MM (2018) Evolution of the open innovation paradigm: towards a contingent conceptual model. Technol Forecast Soc Chang 132:284-298. https://doi.org/10.1016/j. techfore.2018.02.014

Malliet P, Reynes F, Landa G, Hamdi-Cherif M, Saussay A (2020) Assessing short-term and long-term economic and environmental effects of the COVID-19 crisis in France. Environ Resour Econ 76:1-17. https://doi.org/10.1007/s10640-020-00488-z

Martín-Martín A, Orduna-Malea E, Thelwall M, Delgado López-Cózar E (2018) Google Scholar, Web of Science, and Scopus: a systematic comparison of citations in 252 subject categories. J Inform 12(4): 1160-1177. https://doi.org/10.1016/j.joi.2018.09.002

Merigo JM, Yang JB (2017) A bibliometric analysis of operations research and management science. Omega-Int J Manag Sci 73:3748. https://doi.org/10.1016/j.omega.2016.12.004

Mongeon P, Paul-Hus A (2016) The journal coverage of Web of Science and Scopus: a comparative analysis. Scientometrics 106(1):213228. https://doi.org/10.1007/s11192-015-1765-5

Prata JC, Silva ALP, Walker TR, Duarte AC, Rocha-Santos T (2020) COVID-19 pandemic repercussions on the use and management 
of plastics. Environ Sci Technol 54(13):7760-7765. https://doi.org/ 10.1021/acs.est.0c02178

Sarkodie SA, Owusu PA (2020) Impact of COVID-19 pandemic on waste management. Environ Dev Sustain. https://doi.org/10.1007/ s10668-020-00956-y

Sarkodie SA, Strezov V (2019) A review on environmental Kuznets curve hypothesis using bibliometric and meta-analysis. Sci Total Environ 649:128-145. https://doi.org/10.1016/j.scitotenv.2018.08. 276

Shao S, Hu Z, Cao J, Yang L, Guan D (2020) Environmental regulation and enterprise innovation: a review. Bus Strateg Environ 29(3): 1465-1478. https://doi.org/10.1002/bse.2446

Sharma A, Adhikary A, Borah SB (2020) Covid-19's impact on supply chain decisions: strategic insights from NASDAQ 100 firms using Twitter data. J Bus Res 117:443-449. https://doi.org/10.1016/j. jbusres.2020.05.035

Sigala M (2020) Tourism and COVID-19: impacts and implications for advancing and resetting industry and research. J Bus Res 117:312321. https://doi.org/10.1016/j.jbusres.2020.06.015

Tian Z, Tian Y, Chen Y, Shao S (2020) The economic consequences of environmental regulation in China: from a perspective of the environmental protection admonishing talk policy. Bus Strateg Environ 29(4):1723-1733. https://doi.org/10.1002/bse.2464

Tran BX, Vu GT, Ha GI, Vuong QH, Ho MT, Vuong TT et al (2019) Global evolution of research in artificial intelligence in health and medicine: a bibliometric study. J Clin Med 8(3). https://doi.org/10. 3390/jcm8030360

Venter ZS, Aunan K, Chowdhury S, Lelieveld J (2020) COVID-19 lockdowns cause global air pollution declines. Proc Natl Acad Sci U S A 117(32):18984-18990. https://doi.org/10.1073/pnas.2006853117

Verma S, Gustafsson A (2020) Investigating the emerging COVID-19 research trends in the field of business and management: a bibliometric analysis approach. J Bus Res 118:253-261. https:// doi.org/10.1016/j.jbusres.2020.06.057

Wang CJ, Ng CY, Brook RH (2020) Response to COVID-19 in Taiwan big data analytics, new technology, and proactive testing. Jama-J Am Medi Assoc 323(14):1341-1342. https://doi.org/10.1001/ jama.2020.3151
Wang Q, Li R (2017) Research status of shale gas: a review. Renew Sust Energ Rev 74:715-720. https://doi.org/10.1016/j.rser.2017.03.007

Wang Q, Su M (2020a) Integrating blockchain technology into the energy sector - from theory of blockchain to research and application of energy blockchain. Comput Sci Rev 37:100275. https://doi.org/10. 1016/j.cosrev.2020.100275

Wang Q, Su M (2020b) A preliminary assessment of the impact of COVID-19 on environment - a case study of China. Sci Total Environ 728:138915. https://doi.org/10.1016/j.scitotenv.2020. 138915

Wang Q, Wang S (2020) Preventing carbon emission retaliatory rebound post-COVID-19 requires expanding free trade and improving energy efficiency. Sci Total Environ 746:141158. https://doi.org/10. 1016/j.scitotenv.2020.141158

Wang Q, Zhang F (2021) What does the China's economic recovery after COVID-19 pandemic mean for the economic growth and energy consumption of other countries? J Clean Prod 126265:126265. https://doi.org/10.1016/j.jclepro.2021.126265

Xu M, Chen X, Kou G (2019) A systematic review of blockchain. Finan Innovat 5(1):27. https://doi.org/10.1186/s40854-019-0147-Z

Yu YJ, Bu FQ, Zhou HL, Wang YH, Cui JX, Wang X et al (2020) Biosafety materials: an emerging new research direction of materials science from the COVID-19 outbreak. Mater Chem Front 4(7): 1930-1953. https://doi.org/10.1039/d0qm00255k

Zhang K, Shao S, Fan S (2020) Market integration and environmental quality: evidence from the Yangtze river delta region of China. J Environ Manag 261:110208. https://doi.org/10.1016/j.jenvman. 2020.110208

Zhang P, Yan F, Du C (2015) A comprehensive analysis of energy management strategies for hybrid electric vehicles based on bibliometrics. Renew Sust Energ Rev 48:88-104. https://doi.org/ 10.1016/j.rser.2015.03.093

Zuo M (2020) Coronavirus leaves China with mountains of medical waste. South China Morning Post

Publisher's note Springer Nature remains neutral with regard to jurisdictional claims in published maps and institutional affiliations. 